\title{
Modeling the partitioning of organic chemical species in cloud phases with CLEPS (1.1)
}

\author{
Clémence Rose $^{1}$, Nadine Chaumerliac ${ }^{1}$, Laurent Deguillaume ${ }^{1}$, Hélène Perroux ${ }^{1}$, Camille Mouchel-Vallon ${ }^{1, a}$, \\ Maud Leriche $^{2}$, Luc Patryl ${ }^{3}$, and Patrick Armand ${ }^{3}$ \\ ${ }^{1}$ Université Clermont Auvergne, CNRS Laboratoire de Météorologie Physique, 63000 Clermont-Ferrand, France \\ ${ }^{2}$ Université de Toulouse, UPS, CNRS, Laboratoire d'Aérologie, 31400 Toulouse, France \\ ${ }^{3}$ CEA, DAM, DIF, 91297 Arpajon, France \\ ${ }^{a}$ now at: National Center for Atmospheric Research, Boulder, Colorado, USA
}

Correspondence: Laurent Deguillaume (1.deguillaume@opgc.univ-bpclermont.fr)

and Nadine Chaumerliac (n.chaumerliac@opgc.univ-bpclermont.fr)

Received: 26 July 2017 - Discussion started: 10 August 2017

Revised: 2 November 2017 - Accepted: 3 January 2018 - Published: 15 February 2018

\begin{abstract}
The new detailed aqueous-phase mechanism Cloud Explicit Physico-chemical Scheme (CLEPS 1.0), which describes the oxidation of isoprene-derived watersoluble organic compounds, is coupled with a warm microphysical module simulating the activation of aerosol particles into cloud droplets. CLEPS 1.0 was then extended to CLEPS 1.1 to include the chemistry of the newly added dicarboxylic acids dissolved from the particulate phase. The resulting coupled model allows the prediction of the aqueousphase concentrations of chemical compounds originating from particle scavenging, mass transfer from the gas-phase and in-cloud aqueous chemical reactivity. The aim of the present study was more particularly to investigate the effect of particle scavenging on cloud chemistry. Several simulations were performed to assess the influence of various parameters on model predictions and to interpret long-term measurements conducted at the top of Puy de Dôme (PUY, France) in marine air masses. Specific attention was paid to carboxylic acids, whose predicted concentrations are on average in the lower range of the observations, with the exception of formic acid, which is rather overestimated in the model. The different sensitivity runs highlight the fact that formic and acetic acids mainly originate from the gas phase and have highly variable aqueous-phase reactivity depending on the cloud acidity, whereas $\mathrm{C}_{3}-\mathrm{C}_{4}$ carboxylic acids mainly originate from the particulate phase and are supersaturated in the cloud.
\end{abstract}

\section{Introduction}

Clouds are multiphase systems in which a gas phase, an aqueous phase and aerosol particles coexist and interact. As a result, clouds act as huge chemical reactors in which a large variety of both homogeneous and heterogeneous reactions occur. Reactions that would be hindered or occur with a much slower rate in the gas phase take place in the cloud aqueous phase (Herrmann et al., 2015). As indicated by Hegg (2001), the chemical species involved in these reactions originate from the soluble fraction of the aerosol particles on which cloud droplets form (nucleation scavenging) or which are scavenged by the droplets themselves, and from the dissolution of gaseous compounds within the droplets through mass transfer processes. As well demonstrated by Ervens et al. (2015), investigating this in-cloud aqueous reactivity is of great importance to understand global atmospheric chemistry as well as related effects on climate. In fact, the aforementioned reactions may lead to the formation of low-volatility species that can in turn modify the physicochemical properties of aerosol particles after the cloud dissipates and further lead to secondary organic aerosol (SOA) formation and aging (Gelencsér and Varga, 2005; Kanakidou et al., 2005; Lim et al., 2010; Sullivan et al., 2016). The accretion and oxidation of organic compounds were identified as competing aqueous processes responsible for the formation and destruction of SOA precursors (Renard et al., 2015). While accretion processes such as oligomerization have been in the scope of numerous recent studies (Ervens et al., 2015), Mouchel- 
Vallon and coworkers focused on oxidation processes, paying particular attention to the competition between fragmentation and functionalization (Mouchel-Vallon et al., 2017). They developed a protocol to build CLEPS 1.0 (Cloud Explicit Physico-chemical Scheme), a new detailed aqueousphase oxidation mechanism for low- $\mathrm{NO}_{x}$ conditions that is able to describe multiple oxidation pathways for each of the considered $\mathrm{C}_{1}-\mathrm{C}_{4}$ organic species.

This paper describes the coupling between the chemistry model based on CLEPS 1.0 and a bulk two-moment warm cloud microphysical scheme allowing for the simulation of realistic cloud events and comparison with long-term observations. This microphysical scheme predicts both the number concentration and the mixing ratio of cloud droplets and raindrops resulting from the activation of a given aerosol particle spectrum, taking into account the subsequent processes that affect the droplet distribution. The development of such a coupled model first offers the opportunity to investigate the contribution of the particles serving as cloud condensation nuclei (CCN) to aqueous concentrations of given species by nucleation scavenging, which controls the $\mathrm{pH}$ of the droplets and further affects oxidation processes (Leriche et al., 2007; Hegg, 2001). It makes it possible, in particular, to simulate the chemistry of those species that only originate from particle scavenging, such as transition metals (Deguillaume et al., 2005), or that are usually reported as key constituents of the particulate phase, such as dicarboxylic acids (Chebbi and Carlier, 1996). The coupled model can also provide insights into the processing of these particle-originating organic species in the cloud aqueous phase. To make the most of these opportunities, the oxidation pathways of several additional $\mathrm{C}_{4}$ dicarboxylic acids were implemented in CLEPS (V1.1) compared to the initial version of the mechanism introduced in Mouchel-Vallon et al. (2017). In addition to abovementioned nucleation-scavenging-related aspects, the model also allows for the evaluation of the importance of cloud microphysical processes in the redistribution of the reactive compounds among the different phases (gas, cloud and rain) (Leriche et al., 2001). Last but not least, this coupled model is also a unique tool to document the origin of the chemical species measured in cloud water and rainwater (including organics containing up to four carbon atoms), which is usually not available from measurements (Leriche et al., 2007). In fact, the contributions of particle scavenging, mass transfer and aqueous reactivity to simulated aqueous concentrations can be retrieved for all the species described in the model, thus providing highly valuable information to interpret observations.

The model was evaluated against the unique database built on a long-term basis at the Global Atmosphere Watch (GAW) Puy de Dôme (PUY) station to document the cloud water chemical composition, as discussed by Deguillaume et al. (2014). The originality of the present work is to include organic species up to $\mathrm{C}_{4}$ in the comparison between the simulated and measured concentrations; some attempts were per- formed in the past, but with a main focus on inorganic and short-chain organic compounds, and they were moreover often measured during specific short-term field campaigns.

In this paper, the main features of CLEPS 1.1 are first briefly summarized, and the developments in the chemistry of the newly added particle-originating compounds are introduced. Then, the microphysical module based upon the parameterization of Abdul-Razzak and Ghan (2004) and on a bulk cloud scheme previously used by Leriche et al. (2001) is described. The ability of the coupled model to predict concentrations in the range of those measured during cloud events at the PUY station is finally tested.

\section{Model description}

\subsection{The multiphase chemistry model - focus on dicarboxylic acids}

The recent cloud chemistry model based on the explicit aqueous-phase oxidation mechanism CLEPS 1.0 was first introduced in Mouchel-Vallon et al. (2017), where a detailed description can be found.

In addition to the inorganic chemical scheme previously described in Deguillaume et al. (2004) and in Leriche et al. (2007), CLEPS 1.0 describes the $\mathrm{HO}^{\circ}$ and $\mathrm{NO}_{3}{ }^{\circ}$ oxidation pathways of $\mathrm{C}_{1-4}$ organic compounds following the methodology developed by Mouchel-Vallon et al. (2017). CLEPS 1.0 relies on recent improvements in the estimation of kinetic and thermodynamic parameters based on structure-activity relationships (SARs) derived from experimental data (Doussin and Monod, 2013; Minakata et al., 2009; Monod and Doussin, 2008; Raventos-Duran et al., 2010). Mouchel-Vallon and coworkers used these SARs (1) to derive the reaction rates or equilibrium constants of species that were not well documented in the literature and (2) to determine, for the first time, the branching ratios and further select the major oxidation pathways with $\mathrm{HO}^{\bullet}$ to be included in the mechanism. CLEPS 1.0 was coupled to the gas-phase mechanism MCM v3.3.1 (Master Chemical Mechanism) (Jenkin et al., 2015; Saunders et al., 2003), and the exchange between the aqueous and gas phases was accounted for through the kinetic mass transfer theory of stable species following Schwartz (1986).

The whole mechanism, including CLEPS 1.0, MCM v3.3.1 and mass transfer reactions, was integrated in a box model based on DSMACC (Dynamically Simple Model for Atmospheric Chemical Complexity) (Emmerson and Evans, 2009) and using the KPP (Kinetic PreProcessor) (Damian et al., 2002) modified to consider an aqueous phase. The TUV 4.5 radiative transfer model (Madronich and Flocke, 1997) initially set up in DSMACC and dedicated to the calculation of photolysis rates in the gas phase was adapted to include aqueous-phase photolysis reactions. 
For each of the chemical species included in the model, the set of differential equations describing the time evolution of the concentrations in the gas phase and in the cloud aqueous phase is written as

$$
\begin{aligned}
& \frac{\mathrm{d} C_{\mathrm{g}}}{\mathrm{d} t}=P_{\mathrm{g}}-\mathrm{DE}_{\mathrm{g}} C_{\mathrm{g}}+\frac{k_{t_{\mathrm{cw}}} C_{\mathrm{cw}}}{H_{\mathrm{eff}} R T}-q_{\mathrm{cw}} k_{t_{\mathrm{cw}}} C_{\mathrm{g}} \\
& \frac{\mathrm{d} C_{\mathrm{cw}}}{\mathrm{d} t}=P_{\mathrm{cw}}-\mathrm{DE}_{\mathrm{cw}} C_{\mathrm{cw}}+q_{\mathrm{cw}} k_{t_{\mathrm{cw}}} C_{\mathrm{g}}-\frac{k_{t_{\mathrm{cw}}} C_{\mathrm{cw}}}{H_{\mathrm{eff}} R T} .
\end{aligned}
$$

In Eqs. (1) and (2), the subscripts $g$ and cw refer to the gas phase and cloud aqueous phase, respectively, so that $C_{\mathrm{g}}$ and $C_{\mathrm{cw}}$ are, respectively, the gaseous and aqueous chemical concentrations (molec $\mathrm{cm}^{-3}$ ), $P_{\mathrm{g}}$ and $P_{\mathrm{cw}}$, and $\mathrm{DE}_{\mathrm{g}}$ and $\mathrm{DE}_{\mathrm{cw}}$ are, respectively, the gaseous and aqueous chemical production and destruction terms $\left(\mathrm{cm}^{-3} \mathrm{~s}^{-1}\right.$ and $\mathrm{s}^{-1}$, respectively), $H_{\text {eff }}$ is the effective Henry's law constant $\left(\mathrm{M} \mathrm{atm}^{-1}\right)$, $q_{\mathrm{cw}}$ is the cloud liquid water content (vol/vol) and $R=$ $0.08206 \mathrm{~atm} \mathrm{M}^{-1} \mathrm{~K}^{-1} . k_{t_{\mathrm{cw}}}$ is the inverse of the sum of the characteristic times for gaseous diffusion and interfacial mass transport (Schwartz, 1986), expressed as

$k_{t_{\mathrm{cw}}}=\left(\frac{r^{2}}{3 D_{\mathrm{g}}}+\frac{4 r}{3 \bar{v} \alpha}\right)$,

where $r$ is the droplet radius in centimeters, $D_{\mathrm{g}}$ is the gaseous diffusion coefficient $\left(\mathrm{cm}^{2} \mathrm{~s}^{-1}\right)$, and $\bar{v}$ and $\alpha$ are, respectively, the mean quadratic speed in centimeters per second and the accommodation mass coefficient of the species. The effective Henry's law constant accounts for the dissociation or hydration of soluble gases in the aqueous phase, and its determination is thus based upon the use of dissociation and/or hydration constants. These last parameters, together with the Henry's law constant and the accommodation mass coefficient, are prescribed from laboratory measurements or estimated from SARs (Mouchel-Vallon et al., 2017, and references therein). Equations (1) and (2) are solved with a Rosenbrock solver, previously reported to be the most accurate in the frame of multiphase chemistry modeling (Djouad et al., 2002, 2003). The $\mathrm{pH}$ of the droplets is calculated from the concentration of $\mathrm{H}^{+}$, which is explicitly treated in equilibrium reactions solved kinetically with forward and backward reactions.

Developments were made on CLEPS 1.0 to describe the oxidation of dicarboxylic acids that mainly originate from the particle phase and can possibly act as CCN. Dicarboxylic acids are among the best quantified in-particle organic species, though they usually account for only a small fraction of the total organic mass (Saxena and Hildemann, 1996), up to $16 \%$ in remote marine aerosols (Kawamura and Sakaguchi, 1999). While monocarboxylic acids can display concentrations increased by several orders of magnitude in the gas phase compared to the particulate concentrations (Chebbi and Carlier, 1996), dicarboxylic acids are in contrast likely to dominate in the particulate phase as a result of their lower vapor pressure (Ludwig and Klemm, 1988). The presence of low-molecular-weight diacids (such as oxalic acid) in the gas phase was however reported and might be favored under conditions of elevated temperature, low relative humidity and low aerosol pH (Clegg et al., 1996; Kawamura and Kaplan, 1987).

Due to their solubility properties, dicarboxylic acids influence the ability of aerosol particles to act as CCN (Saxena and Hildemann, 1996; Shulman et al., 1996) and, in turn, impact the Earth's radiative budget and climate. Surface tension depression by water soluble dicarboxylic acids in solution was reported by McNeill et al. (2013), involving $\mathrm{C}_{3}$ and $\mathrm{C}_{4}$ compounds such as malonic, malic, succinic and maleic acids. Enhanced reduction effects on the surface tension were observed with the increasing carbon chain length and concentration. Paying particular attention to mixed ammonium sulfate and organic acid (including malonic acid) particles, Abbatt et al. (2005) also showed that the CCN efficiency of the mixed inorganic-organic particles was likely to be significantly modified by solubility effects compared to that of pure inorganic particles. Dicarboxylic acids are of particular interest in the frame of the present study since they can be used as tracers to follow the processing of the whole particulate soluble organic fraction (Ervens et al., 2011), although they only represent a few percent of this soluble organic matter (Legrand et al., 2007).

In this context, the oxidation pathways of succinic, malic, tartric and fumaric-maleic acids were implemented in the model following the protocol described by Mouchel-Vallon et al. (2017). Thus, 65 oxidation reactions and 37 equilibria were newly included in CLEPS and are reported in detail in the tables of the Supplement. These $\mathrm{C}_{4}$ dicarboxylic acids, are, together with oxalic $\left(\mathrm{C}_{2}\right)$, malonic $\left(\mathrm{C}_{3}\right)$ and glutaric $\left(\mathrm{C}_{5}\right.$, not treated in CLEPS) acids, among the main organic compounds measured in aerosol particles in a large variety of environments, including urban (Kawamura and Kaplan, 1987; Kawamura and Yasui, 2005; Kerminen et al., 2000; Limbeck and Puxbaum, 1999; van Pinxteren et al., 2014; Sempére and Kawamura, 1994; Yao et al., 2002), rural (Kerminen et al., 2000; Müller et al., 2005; van Pinxteren et al., 2014), mountainous (Kawamura et al., 2013; Legrand et al., 2007; Limbeck and Puxbaum, 1999), marine (Kawamura and Sakaguchi, 1999; Mochida et al., 2003) and Arctic (Kawamura et al., 2012) atmospheres. Regardless of the site or the season, oxalic acid is always reported to be the most abundant dicarboxylic acid, usually followed by malonic and succinic acids (Chebbi and Carlier, 1996; Mader et al., 2004). For example, these three compounds account, on average, for 60 to $80 \%$ of the diacids measured at European continental sites (Legrand et al., 2007; Müller et al., 2005; van Pinxteren et al., 2014), while oxalic acid alone can represent more than $60 \%$ of these diacids (Legrand et al., 2007).

Sources of dicarboxylic acids include biogenic and anthropogenic emissions, as well as the photochemical transformations of precursors (Chebbi and Carlier, 1996; Dabek- 
Zlotorzynska and McGrath, 2000). While no primary sources have been reported so far for malic and tartric acids, oxalic, malonic, succinic and glutaric acids were measured in motor exhaust (Kawamura and Kaplan, 1987). The last three were also observed in wood burning plumes (Rogge et al., 1998). However, a major fraction of the dicarboxylic acids is likely to be produced by the photochemical oxidation of organic precursors in the atmosphere, occurring in both the gas and aqueous phases (van Pinxteren et al., 2014).

\subsection{Description of the microphysical scheme}

The two-moment warm microphysical scheme predicts the number concentration of cloud droplets and raindrops as well as the mixing ratios of cloud water and rainwater using lognormal distributions (Caro et al., 2004), as previously carried out by Leriche et al. (2007). Only the activation of aerosol particles has been updated to account for the influence of organic surfactants (Abdul-Razzak and Ghan, 2004).

\subsubsection{Activation of aerosol particles into cloud droplets}

Several physically based parameterizations describing the activation of aerosol particles into cloud droplets are available from the literature. Sectional cloud parcel models provide a physically realistic and internally consistent calculation of particle activation and droplet growth in a rising parcel of air. They are however too computationally expensive to be used with detailed explicit aqueous-phase chemistry such as that described in CLEPS 1.0 as we aim in the future to include our developments in regional climate models. The use of parameterizations to estimate the number of activated particles is thus better adapted to this purpose. The most widely used parameterization schemes fall into two families - those based on the work of Abdul-Razzak et al. (1998) and AbdulRazzak and Ghan (2000) and those following Fountoukis and Nenes (2005). The parameterizations provided in these studies differ by the aerosol size distribution they use and the way they treat the activation process. They have been discussed by Simpson et al. (2014) to demonstrate the effect of activating large particles described by a single lognormal mode simulation and by Ghan et al. (2011), who concluded that all parameterizations performed well under the most common conditions, i.e., when $\mathrm{CCN}$ are mainly in the accumulation mode.

In the present study, the activation of aerosol particles into cloud droplets is described using the parameterization from Abdul-Razzak et al. (1998) and Abdul-Razzak and Ghan (2000) and further modified (Abdul-Razzak and Ghan, 2004) to take into account the influence of organic surfactants on the activation process. This last improvement was prompted by the increasing evidence of a significant organic fraction in the chemical composition of aerosol particles (Kanakidou et al., 2005), in particular that of CCN. For instance, a notable amount of organic matter (up to $60 \%$ of the total mass) was detected with a compact time-of-flight aerosol mass spectrometer in the CCN measured at the PUY station (Asmi et al., 2012). Paying more attention to the effect of surfactants on cloud droplet formation follows the global interest that emerged in the literature (McNeill et al., 2013), with a multiplicity of laboratory and field studies as well as global modeling studies (Prisle et al., 2012) dedicated to this research area (Gérard et al., 2016; Nozière et al., 2014).

The parameterizations describing the activation of aerosol particles into cloud droplets developed by Abdul-Razzak et al. (1998) and Abdul-Razzak and Ghan (2000, 2004) are all based upon the Köhler theory (Köhler, 1936) and aim at finding the maximum supersaturation on each model time step considering the physicochemical properties of the aerosol. The Köhler equation describes the balance of water vapor pressure over a growing droplet resulting from two competitive effects: the effects of curvature and surface tension on the one hand (Kelvin term) and the hygroscopicity of the solute on the other (Raoult term). It is assumed in Köhler theory that particles stay in equilibrium with the local supersaturated water vapor until activated as $\mathrm{CCN}$ and thus react instantly to any supersaturation change. Such an assumption might be inexact and lead to overestimation of the droplet number concentrations under certain conditions in which kinetic limitations on droplet growth exist (Nenes et al., 2001). However, when compared with the predictions from an adiabatic parcel model, the parameterizations from Abdul-Razzak et al. (1998) and Abdul-Razzak and Ghan (2000) were reported to predict the cloud activation for updraft velocities higher than $0.5 \mathrm{~m} \mathrm{~s}^{-1}$ and particle number concentrations lower than $500 \mathrm{~cm}^{-3}$ well (Phinney et al., 2003).

While the efficiency of the Köhler equation to model the $\mathrm{CCN}$ behavior of soluble inorganic compounds is recognized, it might be less efficient in predicting the activation of less hygroscopic particles, such as organic or mixed organicinorganic particles. In the last parameterization provided by Abdul-Razzak and Ghan (2004), a modified version of the Köhler theory is used to represent the influence of organic surfactants on aerosol activation. Both recent experimental laboratory and field studies have shown that the presence of such compounds may modify the CCN activity of aerosol particles as a function of the surfactant type and ambient conditions (McNeill et al., 2013).

The treatment of these effects in the parameterization of the activation process is fully described in Abdul-Razzak and Ghan (2004) and only briefly recounted here. Following Shulman et al. (1996), the contributions of inorganic salts and organic surfactants are expressed as a sum in the Raoult term of the modified Köhler theory, assuming additive effects on the vapor pressure. In parallel, the decrease in the surface tension (Kelvin term) is estimated as a function of the surfactant molar concentration using Szyszkowski's empirical formula (Szyszkowski, 1908). Following Li et al. (1998) and earlier work by Corrin and Harkins (1947), the formation of micelles at the droplet surface occurring in the case of high 
surfactant concentrations is also accounted for in the present study.

The aerosol particles to be potentially activated are considered in the model in the form of a multi-lognormal-mode size distribution, as required by Abdul-Razzak and Ghan (2004):

$$
\frac{\mathrm{d} N_{\mathrm{ap}}}{\mathrm{d} \ln d_{\mathrm{ap}}}=\sum_{i=1}^{n} \frac{N_{\mathrm{ap} i}}{\ln \sigma_{i} \sqrt{2 \pi}} \exp \left[-\frac{\ln ^{2}\left(\frac{d_{\mathrm{ap}}}{d_{\mathrm{m} i}}\right)}{2 \ln ^{2} \sigma_{i}}\right],
$$

where $n$ is the number of modes, $N_{\text {ap }}$ is the total number concentration of aerosol particles, $N_{\mathrm{ap} i}$ is the number concentration of aerosol particles in mode $i, d_{\mathrm{m} i}$ is the median diameter of the lognormal distribution for mode $i, \sigma_{i}$ is the geometric standard deviation of the lognormal distribution of mode $i$ and $d_{\text {ap }}$ is the diameter of the aerosol particles.

At each time step, the number of newly nucleated droplets $\left(\frac{\partial N_{\mathrm{cw}}}{\partial t}\right]_{\mathrm{NUC}} \times \Delta t$, where $\Delta t$ is the time step) and the corresponding cloud water mixing ratio are derived from the activated fraction of particles in each mode. To avoid unrealistic supersaturations, the particle size distribution is maintained at constant throughout the simulation, while the maximum particle number and mass to be further activated are constrained in each mode with the initial number and mass concentrations. The aqueous concentrations of particleoriginating chemical species are calculated in the droplet from the soluble fraction of the activated aerosol mass prescribed from measurements.

\subsubsection{Evolution of the cloud droplet distribution - rain formation}

The dynamical framework of the model is an air parcel that mimics the rising of a moist orographic parcel. The evolution of the cloud, including the appearance of rain, is described according to Berry and Reinhardt's parameterization (Berry and Reinhardt, 1974a, b, c, d), as previously performed in Leriche et al. (2001), where more details can be found regarding the use of the parameterization. The resulting twomoment scheme includes the condensation and evaporation of cloud water and rainwater ( $\mathrm{CO})$, the autoconversion of cloud into rain (AU), the accretion of cloud droplets on larger drops (AC), the self-collection of raindrops between themselves (SC), the partial evaporation of cloud droplets and rain drops (EV), and the sedimentation (SED) of raindrops. This leads to the following set of equations for water vapor (subscript v), cloud water (subscript cw) and rainwater (subscript rw).

$$
\begin{aligned}
\frac{\mathrm{d} q_{\mathrm{v}}}{\mathrm{d} t} & \left.\left.\left.=-\frac{\partial q_{\mathrm{cw}}}{\partial t}\right]_{\mathrm{NUC}}-\frac{\partial q_{\mathrm{cw}}}{\partial t}\right]_{\mathrm{CO}}-\frac{\partial q_{\mathrm{rw}}}{\partial t}\right]_{\mathrm{CO}} \\
& \left.\left.+\frac{\partial q_{\mathrm{cw}}}{\partial t}\right]_{\mathrm{EV}}+\frac{\partial q_{\mathrm{rw}}}{\partial t}\right]_{\mathrm{EV}}
\end{aligned}
$$

$$
\begin{aligned}
& \left.\left.\left.\frac{\mathrm{d} N_{\mathrm{cw}}}{\mathrm{d} t}=\frac{\partial N_{\mathrm{cw}}}{\partial t}\right]_{\mathrm{NUC}}-\frac{\partial N_{\mathrm{cw}}}{\partial t}\right]_{\mathrm{AU}}-\frac{\partial N_{\mathrm{cw}}}{\partial t}\right]_{\mathrm{AC}} \\
& \left.-\frac{\partial N_{\mathrm{cw}}}{\partial t}\right]_{\mathrm{EV}} \\
& \left.\left.\left.\frac{\mathrm{d} q_{\mathrm{cw}}}{\mathrm{d} t}=\frac{\partial q_{\mathrm{cw}}}{\partial t}\right]_{\mathrm{NUC}}+\frac{\partial q_{\mathrm{cw}}}{\partial t}\right]_{\mathrm{CO}}-\frac{\partial q_{\mathrm{cw}}}{\partial t}\right]_{\mathrm{AU}} \\
& \left.\left.-\frac{\partial q_{\mathrm{cw}}}{\partial t}\right]_{\mathrm{AC}}-\frac{\partial q_{\mathrm{cw}}}{\partial t}\right]_{\mathrm{EV}} \\
& \left.\left.\left.\frac{\mathrm{d} N_{\mathrm{rw}}}{\mathrm{d} t}=\frac{\partial N_{\mathrm{rw}}}{\partial t}\right]_{\mathrm{AU}}-\frac{\partial N_{\mathrm{rw}}}{\partial t}\right]_{\mathrm{SC}}-\frac{\partial N_{\mathrm{rw}}}{\partial t}\right]_{\mathrm{SED}} \\
& \left.-\frac{\partial N_{\mathrm{rw}}}{\partial t}\right]_{\mathrm{EV}} \\
& \left.\left.\left.\frac{\mathrm{d} q_{\mathrm{rw}}}{\mathrm{d} t}=\frac{\partial q_{\mathrm{rw}}}{\partial t}\right]_{\mathrm{AU}}+\frac{\partial q_{\mathrm{cw}}}{\partial t}\right]_{\mathrm{CO}}+\frac{\partial q_{\mathrm{rw}}}{\partial t}\right]_{\mathrm{AC}} \\
& \left.\left.-\frac{\partial q_{\mathrm{rw}}}{\partial t}\right]_{\mathrm{SED}}-\frac{\partial q_{\mathrm{rw}}}{\partial t}\right]_{\mathrm{EV}}
\end{aligned}
$$

The cloud droplet and raindrop spectra are both represented by single lognormal distributions. The geometric standard deviation of the cloud droplet size distribution is fixed to 0.28 and 0.15 for maritime and continental air masses, respectively, while it remains fixed at 0.547 for the raindrop size distribution regardless of the air mass type (Chaumerliac et al., 1987). In contrast, the median diameters of the distributions are calculated at each time step from the respective water mixing ratios.

\subsection{Coupling the chemistry model with the microphysical scheme}

The initial set of differential Eqs. (1) and (2) has been completed to extend the chemical reactivity and mass transfer to raindrop species (subscript rw):

$$
\begin{aligned}
& \left.\frac{\mathrm{d} C_{\mathrm{g}}^{i}}{\mathrm{~d} t}\right]_{\mathrm{chem}}=P_{\mathrm{g}}-D_{\mathrm{g}} C_{\mathrm{g}}+\frac{k_{t_{\mathrm{cw}}} C_{\mathrm{cw}}}{H^{*} R T}-q_{\mathrm{cw}} k_{t_{\mathrm{cw}}} C_{\mathrm{g}} \\
& \quad+\frac{k_{t_{\mathrm{rw}}} C_{\mathrm{rw}}}{H^{*} R T}-q_{\mathrm{rw}} k_{t_{\mathrm{rw}}} C_{\mathrm{g}} \\
& \left.\frac{\mathrm{d} C_{\mathrm{cw}}^{i}}{\mathrm{~d} t}\right]_{\mathrm{chem}}=P_{\mathrm{cw}}-D_{\mathrm{cw}} C_{\mathrm{cw}}+q_{\mathrm{cw}} k_{t_{\mathrm{cw}}} C_{\mathrm{g}} \\
& \quad-\frac{k_{t_{\mathrm{cw}}} C_{\mathrm{cw}}}{H^{*} R T}+T_{\mathrm{ap}} \\
& \left.\frac{\mathrm{d} C_{\mathrm{rw}}^{i}}{\mathrm{~d} t}\right]_{\mathrm{chem}}=P_{\mathrm{rw}}-D_{\mathrm{rw}} C_{\mathrm{rw}}+q_{\mathrm{rw}} k_{t_{\mathrm{rw}}} C_{\mathrm{g}}-\frac{k_{t_{\mathrm{rw}}} C_{\mathrm{rw}}}{H^{*} R T} .
\end{aligned}
$$

The term $T_{\text {ap }}$ has been introduced in Eq. (10) to take into account the contribution of the soluble fraction of particulate phase to aqueous concentration of species $i$ via particle nucleation scavenging. The rates of change for the chemical concentrations, described by Eqs. (10), (11) and (12), are, with the exception of particle scavenging, driven by the 


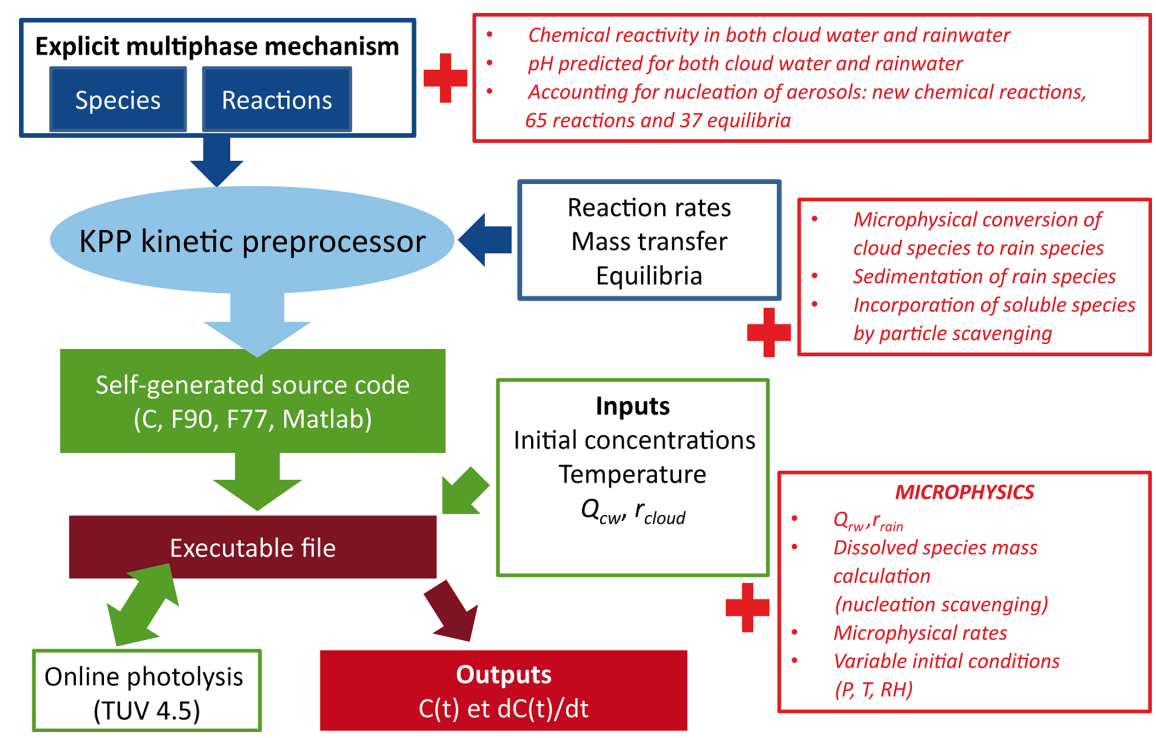

Figure 1. Schematic diagram of CLEPS (Mouchel-Vallon et al., 2017). The developments related to the coupling of CLEPS with the microphysical scheme are shown in red.

chemical reactivity and mass transfer, which are predicted in the chemistry model itself. They will thus hereafter be traced by the subscript "chem" to distinguish from the variations caused by the microphysical conversions related to some of the processes initially accounted for in the microphysical module (see Sect. 2.2.2):

$$
\begin{aligned}
& \left.\frac{\mathrm{d} C_{\mathrm{g}}^{i}}{\mathrm{~d} t}=\frac{\mathrm{d} C_{\mathrm{g}}^{i}}{\mathrm{~d} t}\right]_{\mathrm{chem}} \\
& \left.\left.\left.\frac{\mathrm{d} C_{\mathrm{cW}}^{i}}{\mathrm{~d} t}=\frac{\mathrm{d} C_{\mathrm{cW}}^{i}}{\mathrm{~d} t}\right]_{\mathrm{chem}}-\frac{\mathrm{d} C_{\mathrm{cW}}^{i}}{\mathrm{~d} t}\right]_{\mathrm{AU}}-\frac{\mathrm{d} C_{\mathrm{cW}}^{i}}{\mathrm{~d} t}\right]_{\mathrm{AC}} \\
& \left.\left.\left.\frac{\mathrm{d} C_{\mathrm{rw}}^{i}}{\mathrm{~d} t}=\frac{\mathrm{d} C_{\mathrm{rw}}^{i}}{\mathrm{~d} t}\right]_{\mathrm{chem}}+\frac{\mathrm{d} C_{\mathrm{rw}}^{i}}{\mathrm{~d} t}\right]_{\mathrm{AU}}+\frac{\mathrm{d} C_{\mathrm{rw}}^{i}}{\mathrm{~d} t}\right]_{\mathrm{AC}} \\
& \left.-\frac{\mathrm{d} C_{\mathrm{rw}}^{i}}{\mathrm{~d} t}\right]_{\mathrm{SED}} .
\end{aligned}
$$

For any of the microphysical processes included in the previous equations (autoconversion, accretion, sedimentation), the corresponding rate of change can be written in the form of a proportionality relationship (Chaumerliac et al., 1987; Hegg et al., 1984):

$$
\left.\left.\frac{\mathrm{d} C_{y \mathrm{w}}^{i}}{\mathrm{~d} t}\right]_{Y}=\frac{C_{y \mathrm{w}}^{i}}{q_{y \mathrm{w}}} \frac{\mathrm{d} q_{y \mathrm{w}}}{\mathrm{d} t}\right]_{Y},
$$

where the subscript $y \in\{c, r\}$ describes either cloud or rainwater and the subscript $Y$ refers either to autoconversion, accretion or sedimentation. No term is added for condensation and evaporation because the balance between the gas phase and the aqueous phase is performed by the kinetic mass transfer terms.
An overview of the coupled model is provided in Fig. 1, which highlights the developments performed in the frame of the present work. Many of these developments have to do with the appearance of rainwater in the model, including the duplication of the aqueous oxidation scheme, reaction rates, equilibria and mass transfer, as well as the implementation of new user routines to describe the cloud-to-rain transfer of chemical species (related to autoconversion and accretion processes) and the sink for rain species (related to the sedimentation process). An additional user routine was also developed to treat the input of chemical species in the cloud through CCN particle scavenging.

In practice, the microphysical scheme module is first run to provide a set of look-up tables. These tables contain the time evolution of meteorological variables (temperature, pressure and relative humidity), cloud and rain microphysics (mixing ratio, droplet diameter), and microphysical conversion rates as well as the chemical concentration of the species originating from particle scavenging. In a second stage, the values compiled in the tables are interpolated in time and read as input data by the chemistry model to solve Eqs. (13), (14) and (15) at each time step and for each of the chemical species considered in the model.

\subsection{Initialization of the coupled model}

The ability of the coupled model to predict cloud chemistry, including the processing of organic compounds, and to reproduce concentrations in the range of those measured during real cloud events was tested on an ideal case study. In the frame of the present work, we have chosen to focus on a particular aspect of the developments previously introduced, namely, the contribution of particle scavenging to aqueous 


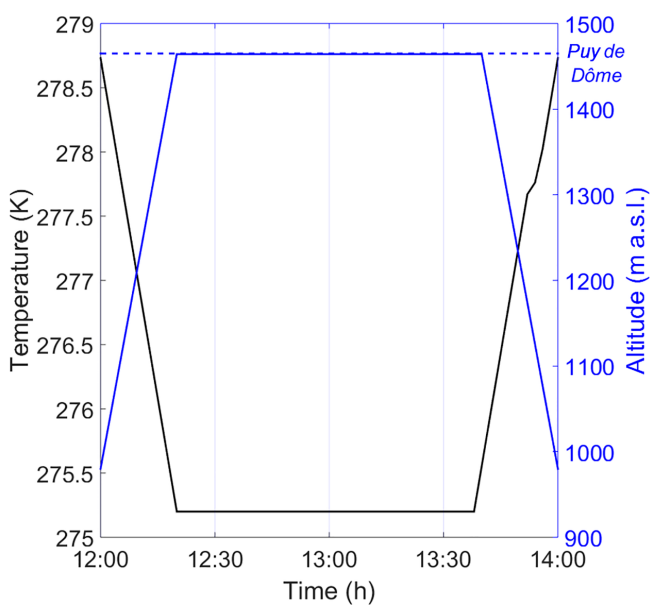

Figure 2. Temperature and altitude profiles prescribed to simulate the occurrence of a non-precipitating orographic cloud at the top of Puy de Dôme mountain.

concentrations and further impacts on the cloud chemistry. A non-precipitating orographic cloud representative of those observed at the PUY station (France, $1465 \mathrm{~m}$ a.s.l.) (Freney et al., 2011) was simulated from the temperature and altitude time profiles shown in Fig. 2 to minimize possible meteorological and rain effects. The understanding of these last effects will be left for further dedicated studies. More complex air mass back-trajectories, such as those provided by a threedimensional model and used by Leriche et al. (2007), might be used in that case.

The initial gas-phase composition was derived from the low- $\mathrm{NO}_{x}$ situation described by McNeill et al. (2012) and is representative of the conditions encountered at the PUY station (Freney et al., 2011). The emission and deposition rates used in the present work are derived from MouchelVallon et al. (2017) and are reported in Table 1. Following the same procedure as Mouchel-Vallon et al. (2017), a gas chemistry spin-up simulation was run for 4.5 days until the appearance of the cloud at noon on the fifth day and the start of the aqueous-phase chemistry.

The physical characteristics of a typical aerosol measured at the PUY station were derived from Sellegri et al. (2003). These data were used to initialize the aerosol particle spectrum as previously carried out in Leriche et al. (2007). The particle size distribution is represented as the sum of four lognormal modes, including an Aitken mode of approximately $76 \mathrm{~nm}$, a first accumulation mode of approximately $410 \mathrm{~nm}$, a second accumulation of mode approximately $660 \mathrm{~nm}$ and a coarse mode of approximately $2.6 \mu \mathrm{m}$. More details on the physical characteristics of these modes (particle number concentration, geometric standard deviation and diameter) can be found in Table 2. The aerosol densities and soluble mass fractions are calculated using the chemical composition of the particles and are also reported in Table 2.
Table 1. Initial gas-phase concentrations, emission and deposition rates adapted from $\mathrm{McNeill} \mathrm{et} \mathrm{al.} \mathrm{(2012).}$

\begin{tabular}{lrrr}
\hline & $\begin{array}{r}\text { Initial } \\
\text { concentration } \\
(\mathrm{ppb})\end{array}$ & $\begin{array}{r}\text { Emission } \\
\left(\mathrm{molec} \mathrm{cm}^{-3} \mathrm{~s}^{-1}\right)\end{array}$ & $\begin{array}{r}\text { Deposition } \\
\left(\mathrm{s}^{-1}\right)\end{array}$ \\
\hline $\mathrm{SO}_{2}$ & 1 & $2.91 \times 10^{5}$ & $5 \times 10^{-5}$ \\
$\mathrm{NO}_{\mathrm{NO}_{2}}$ & - & $2.86 \times 10^{5}$ & - \\
$\mathrm{N}_{2} \mathrm{O}_{5}$ & 0.3 & - & $4 \times 10^{-6}$ \\
$\mathrm{HNO}_{3}$ & - & - & $2 \times 10^{-5}$ \\
$\mathrm{O}_{3}$ & 0.3 & - & $2 \times 10^{-5}$ \\
$\mathrm{H}_{2} \mathrm{O}_{2}$ & 40 & - & $4 \times 10^{-6}$ \\
$\mathrm{CH}_{4}$ & 1 & - & $1 \times 10^{-4}$ \\
$\mathrm{CO}_{2}$ & $1.7 \times 10^{3}$ & - & - \\
$\mathrm{CO}_{\text {Isoprene }}$ & $3.6 \times 10^{5}$ & - & - \\
Dihydroxybutanone & $1.5 \times 10^{2}$ & $3.7 \times 10^{6}$ & $1 \times 10^{-6}$ \\
MACR & 1 & $4.50 \times 10^{6 *}$ & - \\
MVK & - & - & $1 \times 10^{-5}$ \\
$\mathrm{Glyoxal}_{\text {Methylglyoxal }}^{2}$ & - & - & $1 \times 10^{-5}$ \\
Glycolaldehyde & - & - & $1 \times 10^{-5}$ \\
Acetaldehyde & 0.1 & - & $1 \times 10^{-5}$ \\
Formaldehyde & 0.1 & - & $1 \times 10^{-5}$ \\
Acetone & - & - & $1 \times 10^{-5}$ \\
Pyruvic acid & 0.1 & $3.17 \times 10^{3}$ & $1 \times 10^{-5}$ \\
Acetic acid & 0.5 & $3.03 \times 10^{3}$ & $1 \times 10^{-5}$ \\
Formic acid & 0.1 & $8.92 \times 10^{3}$ & $1 \times 10^{-5}$ \\
Methanol & - & - & $1 \times 10^{-5}$ \\
Methyl hydroperoxide & $1 \times 10^{-3}$ & $3.35 \times 10^{3}$ & $1 \times 10^{-5}$ \\
\hline & - & - & $1 \times 10^{-5}$ \\
& 2 & $1.07 \times 10^{4}$ & $1 \times 10^{-5}$ \\
\hline 0 & 0.01 & $3.35 \times 10^{3}$ & $1 \times 10^{-5}$ \\
\hline
\end{tabular}

$*-0$ at nighttime.

The chemical composition of the particles was prescribed according to the measurements conducted between 28 February and 1 March 2000 by Sellegri et al. (2003) in a moderately polluted air mass (see Table 3 ). Particles were sampled using a low-pressure cascade impactor (13-stage ELPI impactor, commercialized by Dekati Inc.) and were further analyzed using ion chromatography. The mass fraction of iron was derived from particle-induced X-ray emission. More details on the sampling procedure and data analysis can be found in Sellegri et al. (2003).

The mass distribution of the dicarboxylic acids derived from these measurements is shown in Fig. S1 in the Supplement. As expected, oxalic acid is the most abundant and the major fraction of the diacids found in the two accumulation modes $(0.4-1 \mu \mathrm{m})$, as previously observed at other continental European sites (Legrand et al., 2007; Müller et al., 2005; van Pinxteren et al., 2014). When comparing these concentrations with those obtained at the PUY station during the CARBOSOL project (Present and Retrospective State of Organic versus Inorganic Aerosol over Europe: Implications for Climate) by Legrand et al. (2007), we found a fair agreement for succinic (this study: $5.98 \mathrm{ng} \mathrm{m}^{-3}$, Legrand et al., 2007: $\left.6.8 \pm 8.1 \mathrm{ng} \mathrm{m}^{-3}\right)$ and tartric $\left(1.53 \mathrm{ng} \mathrm{m}^{-3}\right.$ vs. $\left.1.6 \pm 2.8 \mathrm{ng} \mathrm{m}^{-3}\right)$ acids. In contrast, malic $\left(2.2 \mathrm{ng} \mathrm{m}^{-3}\right.$ vs. 
Table 2. Physical properties of aerosol particles. For each mode $N_{\text {ap }}$ is the particle concentration, $d_{\mathrm{m}}$ is the median diameter, $\sigma$ is the geometric standard deviation, $\rho_{\mathrm{ap}}$ is the density of aerosols and $\varepsilon$ is the soluble fraction of the mode.

\begin{tabular}{lrrrrr}
\hline Mode & $N_{\text {ap }}\left(\mathrm{cm}^{-3}\right)$ & $d_{\mathrm{m}}(\mu \mathrm{m})$ & $\log \sigma$ & $\rho_{\text {ap }}\left(\mathrm{g} \mathrm{cm}^{-3}\right)$ & $\varepsilon(\%)$ \\
\hline 1 & 111.9 & 0.076 & 0.255 & 1.62 & 46.0 \\
2 & 4.2 & 0.410 & 0.278 & 1.67 & 63.3 \\
3 & 1.5 & 0.660 & 0.041 & 1.73 & 78.8 \\
4 & 0.026 & 2.6 & 0.301 & 1.71 & 77.3 \\
\hline
\end{tabular}

Table 3. Chemical composition of aerosol particles. Each species is given with its contribution to the soluble mass in each mode $\left(\varepsilon_{\text {spc }}\right)$, its molar mass $\left(M_{\mathrm{spc}}\right)$ and the number of ions into which it may dissociate $\left(v_{\mathrm{spc}}\right)$.

\begin{tabular}{lrrrrrr}
\hline & \multicolumn{5}{c}{$\varepsilon_{\text {spc }}(\%)$} & \multirow{2}{*}{$\mathcal{v}_{\text {spc }} M_{\text {spc }}\left(\mathrm{g} \mathrm{mol}^{-1}\right)$} \\
\cline { 2 - 5 } & Mode 1 & Mode 2 & Mode 3 & Mode 4 & & \\
\hline $\mathrm{NO}_{3}^{-}$ & $1.39 \times 10^{1}$ & $1.58 \times 10^{1}$ & $1.58 \times 10^{1}$ & $2.73 \times 10^{1}$ & 1 & 62.0 \\
$\mathrm{NH}_{4}^{+}$ & 6.96 & $1.72 \times 10^{1}$ & $2.77 \times 10^{1}$ & 1.01 & 1 & 18.0 \\
$\mathrm{SO}_{4}^{2-}$ & $1.66 \times 10^{1}$ & $2.65 \times 10^{1}$ & $3.96 \times 10^{1}$ & $2.18 \times 10^{1}$ & 2 & 96.0 \\
$\mathrm{Na}^{+}$ & 1.24 & $3.86 \times 10^{-1}$ & $9.44 \times 10^{-1}$ & $1.80 \times 10^{1}$ & 1 & 23.0 \\
$\mathrm{Cl}^{-}$ & 4.11 & $2.97 \times 10^{-1}$ & $2.27 \times 10^{-1}$ & 6.15 & 1 & 35.5 \\
Iron* & 0.00 & $6.93 \times 10^{-2}$ & $1.40 \times 10^{-1}$ & $3.38 \times 10^{-1}$ & 1 & 73.0 \\
Formate & $4.15 \times 10^{-1}$ & $4.12 \times 10^{-1}$ & $5.38 \times 10^{-1}$ & 2.47 & 1 & 46.0 \\
Oxalate & $3.65 \times 10^{-1}$ & 1.19 & 1.21 & 2.23 & 1 & 88.0 \\
Acetate & 1.38 & $1.38 \times 10^{-1}$ & $8.43 \times 10^{-2}$ & 1.47 & 1 & 59.0 \\
Glycolate & $2.15 \times 10^{-1}$ & $1.16 \times 10^{-1}$ & $7.58 \times 10^{-2}$ & $1.26 \times 10^{-1}$ & 1 & 75.0 \\
Glyoxylate & $1.22 \times 10^{-1}$ & $5.66 \times 10^{-2}$ & $1.40 \times 10^{-1}$ & $2.06 \times 10^{-1}$ & 1 & 73.0 \\
Lactate & $1.23 \times 10^{1}$ & 4.72 & 1.93 & 7.19 & 1 & 89.0 \\
Propionate & $1.87 \times 10^{-1}$ & $2.27 \times 10^{-1}$ & $2.22 \times 10^{-1}$ & $3.88 \times 10^{-1}$ & 1 & 73.0 \\
Malonate & 0.00 & $2.09 \times 10^{-2}$ & $7.28 \times 10^{-2}$ & $7.40 \times 10^{-2}$ & 2 & 103.0 \\
Succinate & $2.82 \times 10^{-1}$ & $2.59 \times 10^{-1}$ & $2.06 \times 10^{-1}$ & $3.72 \times 10^{-1}$ & 2 & 117.0 \\
Malate & 0.00 & $1.08 \times 10^{-1}$ & $1.28 \times 10^{-1}$ & $2.80 \times 10^{-2}$ & 2 & 133.0 \\
Tartrate & 0.00 & $4.43 \times 10^{-2}$ & $5.18 \times 10^{-2}$ & $1.34 \times 10^{-1}$ & 2 & 149.0 \\
\hline
\end{tabular}

* An iron solubility of $15 \%$ was assumed according to Deguillaume et al. (2005).

$\left.4.9 \pm 5.7 \mathrm{ng} \mathrm{m}^{-3}\right)$, oxalic $\left(29.8 \mathrm{ng} \mathrm{m}^{-3}\right.$ vs. $\left.80 \pm 90 \mathrm{ng} \mathrm{m}^{-3}\right)$ and malonic $\left(1.31 \mathrm{ng} \mathrm{m}^{-3}\right.$ vs. $\left.13.8 \pm 20.2 \mathrm{ng} \mathrm{m}^{-3}\right)$ acids were reported to be, on average, more abundant during the CARBOSOL project. The concentrations measured at the PUY station display intermediate values compared to those reported by Legrand et al. (2007) for the altitude sites of Schauinsland (Germany, $1205 \mathrm{~m}$ a.s.l.) and Vallot (French Alps, $4360 \mathrm{~m}$ a.s.l.). They are also in the range of the values reported by Müller et al. (2005) for the Goldauter station (605 m a.s.l.) located close to Schmücke (Germany) and slightly lower than those recently measured at the same place by van Pinxteren et al. (2014).

All the species measured in the particulate phase and implemented in the initialization of the coupled model are listed in Table 3 with their contribution to the soluble mass fraction in each mode, their molar mass and the number of ions into which they may dissociate.

\section{Results and discussion}

\subsection{Microphysical evolutions}

Figure 3 shows the time evolution of the simulated cloud liquid water content (LWC) and mean cloud droplet radius. It should be noted that the appearance of the cloud was scheduled around noon, when the photolysis rates are at their maximum, to favor enhanced photochemistry. Apart from the condensation and evaporation phases, the LWC is close to $0.4 \mathrm{~g} \mathrm{~m}^{-3}$, with an average value of $0.3 \mathrm{~g} \mathrm{~m}^{-3}$ calculated from the whole simulation. A constant cloud droplet radius of $9.5 \mu \mathrm{m}$ is obtained all along the stable phase of the cloud lifetime, between 12:20 and 13:40 LT. These values are in good agreement with the typical values measured at the PUY station from 2001 onwards, which can be found in a database including 110 cloud events that is available online at http://www.obs.univ-bpclermont.fr/SO/beam/data. php. Indeed, based on this large dataset, the LWC measured 
Table 4. Chemical concentrations, $\mathrm{pH}$ and cloud liquid water content (LWC) measured in clouds sampled at Puy de Dôme and calculated by the model during the six different runs. Main characteristic settings are recalled for each run.

\begin{tabular}{|c|c|c|c|c|c|c|c|c|c|c|c|c|}
\hline \multirow[b]{3}{*}{$\begin{array}{l}\text { Concentration } \\
(\mu \mathrm{M})\end{array}$} & \multicolumn{6}{|c|}{ Observations } & & & & & & \\
\hline & \multicolumn{3}{|c|}{ Marine } & \multicolumn{3}{|c|}{ Highly marine } & & & Model si & nulations & & \\
\hline & Mean & Min & Max & Mean & Min & Max & $\begin{array}{r}\text { Run } 1 \\
\text { Reference }\end{array}$ & $\begin{array}{r}\text { Run } 2 \\
\text { No particle } \\
\text { scavenging }\end{array}$ & $\begin{array}{r}\text { Run } 3 \\
\text { Increased } \\
\text { amount of } \\
\text { organics in } \\
\text { particle phase }\end{array}$ & $\begin{array}{r}\text { Run } 4 \\
\text { Formation of } \\
\text { iron oxalate } \\
\text { complexes } \\
\text { turned off }\end{array}$ & $\begin{array}{r}\text { Run } 5 \\
\text { Decreased cloud } \\
\text { liquid water } \\
\text { content and } \\
\text { droplet radius }\end{array}$ & $\begin{array}{r}\text { Run } 6 \\
\mathrm{pH}=6\end{array}$ \\
\hline Sulfate & 14.15 & 1.95 & 38.6 & 39.65 & 9.4 & 130.8 & 37.31 & 29.99 & 36.70 & 36.70 & 49.13 & 37.31 \\
\hline Nitrate & 24.8 & 0.8 & 93.2 & 59.3 & 9.7 & 231.8 & 11.96 & 2.48 & 11.12 & 11.12 & 15.88 & 11.96 \\
\hline Formate & 6.3 & 0.8 & 29 & 13 & 2.3 & 42.4 & 20.52 & 19.83 & 20.56 & 20.46 & 23.59 & 25.84 \\
\hline Acetate & 4.9 & 0.3 & 22.2 & 12 & 1.8 & 57.6 & 3.41 & 3.31 & 3.42 & 3.39 & 3.45 & 12.50 \\
\hline Oxalate & 2.1 & 0.2 & 7.5 & 3.6 & 1.5 & 12 & 0.49 & 0.05 & 2.32 & 2.55 & 0.64 & 0.47 \\
\hline Succinate & 0.6 & & 3.5 & 1.1 & 0 & 4.5 & 0.06 & 0 & 0.15 & 0.15 & 0.09 & 0.06 \\
\hline $\mathrm{pH}$ & 5.7 & 4.6 & 7.6 & 6.2 & 4.7 & 6.9 & 4.37 & 4.36 & 4.38 & 4.36 & 4.29 & 6.00 \\
\hline
\end{tabular}

at the PUY station exhibits rather limited variation, with an average value of $0.28 \pm 0.12 \mathrm{~g} \mathrm{~m}^{-3}$, while the droplet radius is on average approximately $10 \mu \mathrm{m}$ (Deguillaume et al., 2014). Deguillaume et al. (2014) classified the cloud samples using a statistical analysis methodology that takes into account the physicochemical parameters of the cloud together with the back-trajectories of the sampled air masses. Cloud events in the westerly and northerly-northwesterly air masses were the most frequent, representing $72 \%$ of the air masses sampled at the PUY station, the majority of which were categorized as "marine" or "highly marine". These two categories of cloud events displayed high $\mathrm{pH}$ values compared to other types, namely "polluted" and "continental" (mean pH 5.7, 6.2, 4.0 and 4.9 in marine, highly marine, polluted and continental clouds, respectively). In addition, highly marine cases were characterized by high concentrations of $\mathrm{Na}^{+}$ and $\mathrm{Cl}^{-}$(means of 311 and $232 \mu \mathrm{M}$, respectively), which were, in contrast, 1 order of magnitude lower in marine cases (means of 32 and $30 \mu \mathrm{M}$, respectively). The clouds sampled in the westerly-southwesterly air masses were also frequently characterized by a strong marine signature $(64 \%)$. Since the aerosol particle spectrum to be activated was measured in such an air mass, the model results will be compared to the marine and highly marine cases classified by Deguillaume et al. (2014).

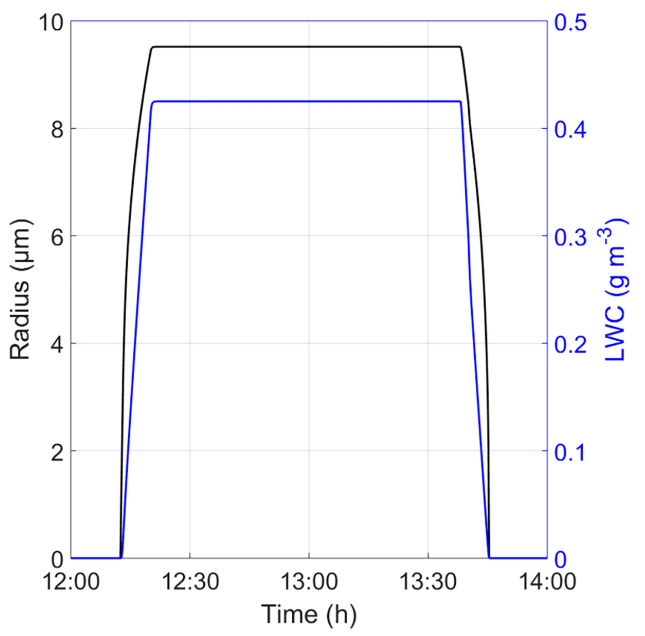

Figure 3. Time evolution of the mean cloud droplet radius (left axis) and cloud liquid water content (right axis).

\subsection{Comparison of simulated and measured in-cloud chemical concentrations - discussion and sensitivity studies}

\subsubsection{Importance of particle scavenging in cloud water chemical composition}

In Table 4, the simulated cloud water chemical concentrations are compared with those measured in marine and highly marine clouds observed at the PUY station $(\sim 70$ cloud events) for a set of compounds (Deguillaume et al., 2014). The concentrations measured during highly marine cases are on average higher for both inorganic and organic species 
compared to marine ones, also with a higher $\mathrm{pH}$ but similar LWC. The modeled concentrations are average values calculated throughout the simulation apart from the condensation and evaporation phases to be close to the measuring conditions in a well-formed cloud (this period roughly corresponds to the plateau displayed in Figs. 2 and 3).

The agreement between the measured and modeled hydrogen peroxide concentrations is weak. Several reasons related to measurement conditions can explain this discrepancy. In marine air masses, measured hydrogen peroxide concentration is very variable (standard deviation $=7.12$ and $6.31 \mu \mathrm{M}$ for highly marine and marine clouds, respectively). Additionally, during the wintertime, the hydrogen peroxide concentration is often derived from frozen samples (Marinoni et al., 2011; Snider et al., 1992), which, as demonstrated in the aforementioned studies, can lead to an underestimation of the actual in-cloud concentration because of the outgassing of $\mathrm{H}_{2} \mathrm{O}_{2}$. In addition to measurement issues, we observed that the gas-phase chemistry model used in this work (MCM) produces a large amount of $\mathrm{H}_{2} \mathrm{O}_{2}$ under our chemical scenario. The discrepancy between the observed and modeled $\mathrm{H}_{2} \mathrm{O}_{2}$ values could also arise from the presence of microorganisms, not yet considered in the model, that efficiently degrade $\mathrm{H}_{2} \mathrm{O}_{2}$ as well as formic acid (Vaïtilingom et al., 2013).

In contrast, fair agreement is found between the model results and observations for inorganic species, except for the nitrate level, which is underestimated but still in the range of measurements. Under low- $\mathrm{NO}_{x}$ conditions, nitrate formation due to gas-phase chemistry (mass transfer) competes with nitrate formation through particle scavenging, as described later in Sect. 3.3. Additionally, nitric acid is very soluble and therefore sensitive to microphysical parameters (i.e., it would be more concentrated with lower cloud water content and smaller cloud droplets).

For the dicarboxylic acids, the model predicts concentrations that are lower compared to those measured on average at PUY. These discrepancies might, at least partly, arise from the aerosol particle spectrum used to initialize the model, which exhibited organic contents in the low range of the typical measurements. The reason for the low simulated oxalate concentrations compared to the measured ones, even when particle scavenging is accounted for in the model, may also lie in the formation of iron-oxalate complexes and their efficient photolysis. It is likely that the formation of these ironoxalate complexes is overestimated by the model due to an incomplete coverage of the iron complexation processes with other compounds in CLEPS. The absence of competition between different ligands to form iron complexes in CLEPS leads to a high amount of free iron available to form complexes with oxalate ions, and in turn lower oxalate concentrations.

To evaluate the effect of nucleation scavenging of $\mathrm{CCN}$ particles on the cloud chemistry, a sensitivity simulation was performed without taking into account particle scavenging. The results are shown in Table 4 (Run 2) and compared to the reference simulation (Run 1). As mentioned before, particles serving as nuclei for the formation of cloud droplets can dissolve in the cloud water and modify its chemical content. This is particularly true for ammonia and strong acids (sulfuric and nitric acids), as well as for dicarboxylic acids (oxalic, succinic and malonic acids). Indeed, particle scavenging is a major contributor of acidic content in the cloud, as highlighted by the comparison of Run 1 and Run 2 in Table 4: for instance, the nitrate concentration is reduced from 12 to $2.5 \mu \mathrm{M}$ when neglecting the scavenging of particulate nitrate in the model. The effect is less obvious for sulfate because its concentration is mostly controlled by the sulfur dioxide reactivity and to a lesser extent by the scavenging of particulate sulfate, as discussed later (Sect. 3.3).

To obtain more insight into the impact of particle scavenging on the aqueous carboxylic acid concentrations, an additional simulation was conducted. This test (Run 3) was performed using the mean particulate concentrations measured by Legrand et al. (2007) at the PUY station for oxalic, succinic, malonic, malic and tartric acids (see Supplement), while all other concentrations and parameters were left unchanged when initializing the model. The concentrations provided by Legrand et al. (2007) were, however, given as a sum over the whole particle size distribution. We thus assumed that the relative contributions of each mode to the total concentration of the diacids listed above were similar to those observed during the reference case study to calculate the distribution of these acids and further initialize the model. These relative contributions as well as the concentrations provided by Legrand et al. (2007) are provided in Table S1 in the Supplement. As shown in Fig. S2 and Table S1, the concentrations from Legrand et al. (2007) are higher compared to those used in Run 1, especially for oxalic, malonic, and malic acids and to a lesser extent for succinic and tartric acids. Figure 4 presents the simulated concentrations from Runs 1 and 3 for those species.

The increased amount of organic matter in the particulate phase did not affect the cloud microphysical properties, namely the cloud LWC and droplet radius, which were determined rather by the dominant inorganic fraction representative of marine aerosols. In contrast, as expected, the carboxylic acid concentrations are increased in Run 3, when using data from Legrand et al. (2007), and the agreement between the modeled and measured concentrations is especially increased for oxalic and malonic acids (see Table 4). The simulated oxalate concentration is also significantly increased and matches well with the average value representative of highly marine clouds, but it remains in the lower range of marine concentrations. As previously mentioned, the discrepancy between the modeled and measured oxalate concentrations might also be related to an overestimated formation of iron-oxalate complexes in the model because of some missing iron complexation processes in CLEPS. To verify this hypothesis, a new run (Run 4) was performed, similar to Run 3, i.e., with increased carboxylic acid con- 


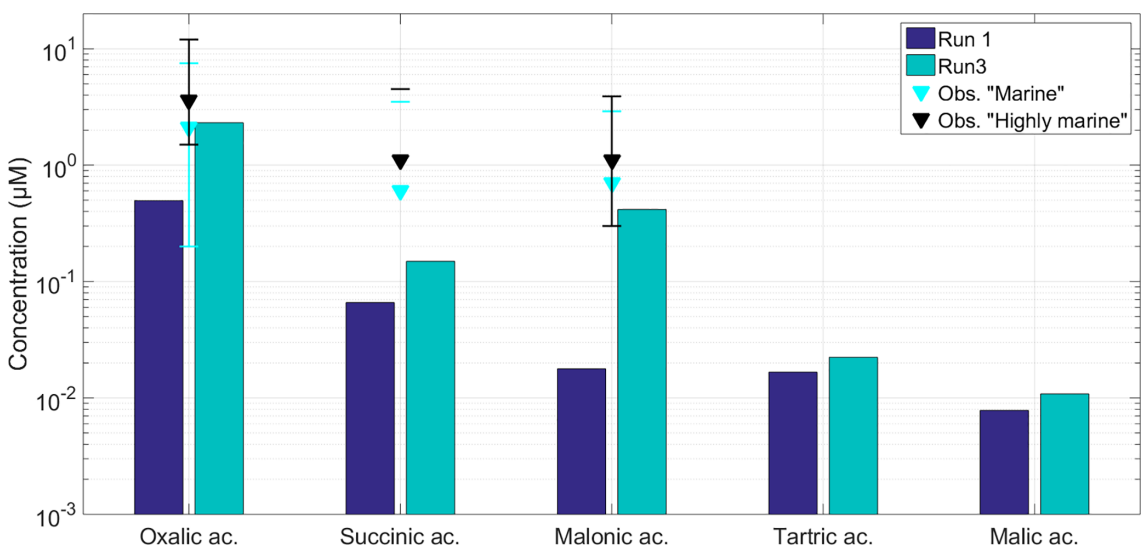

Figure 4. Averaged concentrations of some carboxylic acids calculated by the model during Run 1 (reference) and Run 3 (increased quantities of organics in the particle phase). When available, the concentrations measured in marine and highly marine clouds sampled at Puy de Dôme and reported by Deguillaume et al. (2014) are shown for comparison. Markers represent the mean concentrations, while lower and upper limits of the error bars respectively show the minimum and maximum concentrations measured at this site. For succinic acid, the minimum concentration was below the detection limit of the instrument and is thus not shown.

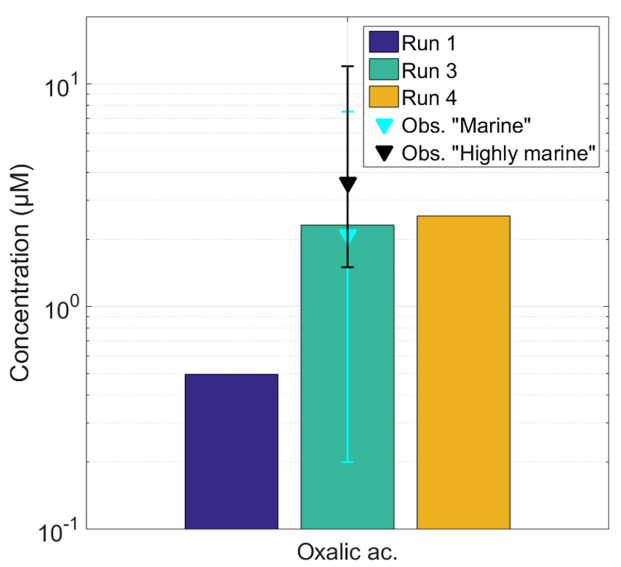

Figure 5. Averaged concentrations of oxalic acid calculated by the model during Run 1 (reference), Run 3 (increased quantities of organics in the particle phase) and Run 4 (same as Run 3 but with formation of iron-oxalate complexes turned off). Concentrations measured in marine and highly marine clouds sampled at Puy de Dôme (Deguillaume et al., 2014) are reported for comparison. Markers represent the mean concentrations, while lower and upper limits of the error bars respectively show the minimum and maximum concentrations measured at this site.

centrations in the particulate phase, but with the iron-oxalate chemistry turned off. However, as shown in Fig. 5, the ironoxalate chemistry has a smaller influence on the oxalic acid concentration than nucleation scavenging of $\mathrm{CCN}$ particles. This low sensitivity to iron-complexation chemistry may be due to the very low dissolved iron content in the cloud water $\left(7.6 \times 10^{-2} \mu \mathrm{M}\right)$. It can also be argued that sources of oxalic acid related to the oxidation of compounds not yet considered in the chemical mechanism are missing in the model.

\subsubsection{Sensitivity study regarding cloud microphysics and acidity}

A last series of tests was performed to assess the effects of other known sensitive parameters on the model results, namely the cloud LWC and the droplet radius (Run 5) as well as the $\mathrm{pH}$ (Run 6). The results of these sensitivity tests are reported in Table 4. Soluble species are very responsive to the cloud LWC and are more concentrated in the aqueous phase when the cloud droplet radius is smaller. As a consequence, most of the chemical species shown in Table 4 display increased concentrations when the LWC and the droplet radius are both lowered (from 0.39 to $0.29 \mathrm{~g} \mathrm{~m}^{-3}$ and from 9.5 to $8.6 \mu \mathrm{m}$, respectively). Additionally, the resulting $\mathrm{pH}$ in Run 5 is more acidic than that in Run 1.

According to Deguillaume et al. (2014), the mean pH in marine clouds is 5.7 , and it is 6.2 for the highly marine ones (Table 4). The lower values obtained during Run 1 are most likely explained by the fact that for the simulation of marine air masses, the model should take into account more cations $\left(\mathrm{Na}^{+}, \mathrm{Mg}^{2+}, \mathrm{K}^{+}, \mathrm{Ca}^{2+}\right)$. Those are currently missing in CLEPS, in which recent developments were rather focused on organic chemistry. As previously mentioned, the $\mathrm{H}^{+}$concentration is presently calculated in the model based on acido-basic equilibria. To further test the effect of the $\mathrm{pH}$ on cloud chemistry, we performed an additional run, Run 6 , throughout, which we imposed a $\mathrm{pH}$ of 6 , i.e., closer to the measured values.

As shown in Fig. 6, increasing the $\mathrm{pH}$ has a great influence on weak acids, i.e., organic acids. The acetic acid concentration is much higher when the $\mathrm{pH}$ is less acidic, consistent with observations from the marine and highly marine cases. The acidic form $\left(\mathrm{CH}_{3} \mathrm{CO}(\mathrm{OH})\right)$ is dominant as the $\mathrm{pH}$ is more acidic (Run 1), whereas the contribution of the anionic form $\left(\mathrm{CH}_{3} \mathrm{CO}\left(\mathrm{O}^{-}\right)\right)$is increased at $\mathrm{pH}=6$ 


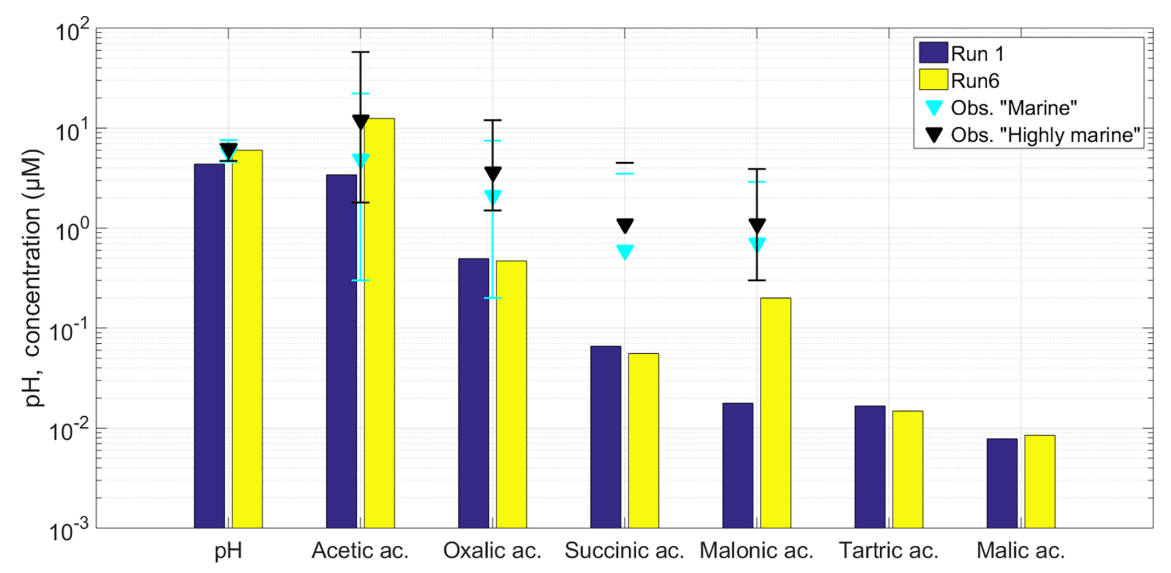

Figure 6. Averaged concentrations of some carboxylic acids calculated by the model during Run 1 (reference) and Run 6 (pH=6). When available, the concentrations measured in marine and highly marine clouds sampled at Puy de Dôme and reported by Deguillaume et al. (2014) are shown for comparison. Markers represent the mean concentrations, while lower and upper limits of the error bars respectively show the minimum and maximum concentrations measured at this site. For succinic acid, the minimum concentration was below the detection limit of the instrument and is thus not shown.

(Run 6). Both forms are produced by the reaction of pyruvic acid with hydrogen peroxide in the cloud aqueous phase, but at rates that differ significantly, with $0.12 \mathrm{M}^{-1} \mathrm{~s}^{-1}$ for the acidic form $\left(\mathrm{CH}_{3} \mathrm{COCO}(\mathrm{OH})\right)$ and $0.75 \mathrm{M}^{-1} \mathrm{~s}^{-1}$ for the anionic form $\left(\mathrm{CH}_{3} \mathrm{COCO}\left(\mathrm{O}^{-}\right)\right)$. As a result, the total aqueous production of acetic acid is enhanced when the $\mathrm{pH}$ is higher. The formic acid concentration is also larger when the $\mathrm{pH}$ is less acidic (Run 6, Table 4), which is due to stronger sources mainly related to the oxidation of formaldehyde, glyoxal and glycolaldehyde by $\mathrm{HO}^{\bullet}$ radicals. When the $\mathrm{pH}=6$, the $\mathrm{HO}^{\circ}$ concentration is doubled (from $4 \times 10^{-14} \mathrm{M}$ in Run 1 to $9 \times 10^{-14} \mathrm{M}$ in Run 6) compared to that when the $\mathrm{pH}$ is approximately 4.3 since the decomposition of ozone by the dominant anionic form of $\mathrm{HO}_{2}{ }^{\circ}$ is more efficient to produce $\mathrm{HO}^{\bullet}$ radicals.

\subsection{Partitioning and sources of chemical species (mass transfer from gas phase, particle scavenging and aqueous-phase reactivity)}

\subsubsection{Partitioning among gas-aqueous cloud phases}

In this section, the partitioning between the gas and aqueous phases is discussed in detail for some species. It can be represented by a partitioning coefficient $q$ defined by Audiffren et al. (1998) based upon the phase ratio introduced by Chameides (1984) and Lelieveld and Crutzen (1991):

$q=\frac{C_{\mathrm{aq}}(i)}{q_{\mathrm{cw}} H_{\mathrm{eff}}(i) R T C_{\mathrm{g}}(i)}$,

where $C_{\mathrm{g}}(i)$ and $C_{\mathrm{aq}}(i)$ are, respectively, the gaseous and aqueous concentrations of species $i$ in molec $\mathrm{cm}^{-3}, q_{\mathrm{cw}}$ is the LWC in vol/vol, $H_{\text {eff }}(i)$ is the effective Henry's law constant of species $i$ in $\mathrm{M} \mathrm{atm}^{-1}$ and $R=0.08206 \mathrm{~atm} \mathrm{M}^{-1}$ $\mathrm{K}^{-1}$. This factor $q$ indicates whether species $i$ is at the
Henry's law equilibrium $(q=1)$, undersaturated in the aqueous phase $(q<1)$ or supersaturated in the aqueous phase $(q>1)$.

The partitioning between the gas and aqueous phases cannot be described by a thermodynamic equilibrium assumption. The factor $q$ evolves with time, as microphysical processes, mass transfer and chemical reactivity modify the partitioning of the species in the gas and aqueous phases. However, to get more insight into this partitioning, mean $q$ values were calculated for several species over the whole cloud duration and are shown, together with their effective Henry's law constants, in Fig. 7 for Run 1 (variable $\mathrm{pH}$ approximately 4.3) and $\mathrm{Run} 6(\mathrm{pH}=6)$.

As highlighted by Ervens (2015), most of the species represented in Fig. 7 are distributed among gas and aqueous phases with respect to Henry's law (i.e., $q=1$ ) since the clouds that are represented in the simulations have a small cloud radius around $10 \mu \mathrm{m}$. However, some deviations from partitioning according to Henry's law are observed over a wide range of solubility for species like $\mathrm{SO}_{2}, \mathrm{HNO}_{4}, \mathrm{HNO}_{3}$, $\mathrm{H}_{2} \mathrm{SO}_{4}$ and this deviation increases with increasing $\mathrm{pH}$. Then, the partitioning of highly soluble carbonyl compounds (glyoxal, formaldehyde, etc.) can be described within a factor between 2 and 100 by their effective Henry's law constant.

Using CAPRAM, Tilgner and Herrmann (2010) identified glyoxal as one of the important gas-phase precursors to carbonyl compounds and acids in clouds and Ginnebaugh and Jacobson (2012) show that using the glyoxal Henry's constant updated by Ip et al. (2009) has a great impact, increasing total glyoxylic acid concentrations by up to $29 \%$. Glyoxylic acid is mostly found in the aqueous phase under its anionic and hydrated forms. At high $\mathrm{pH}$ (Run 6), the anionic form is dominant and favors the presence of glyoxylic acid in the aqueous phase. 


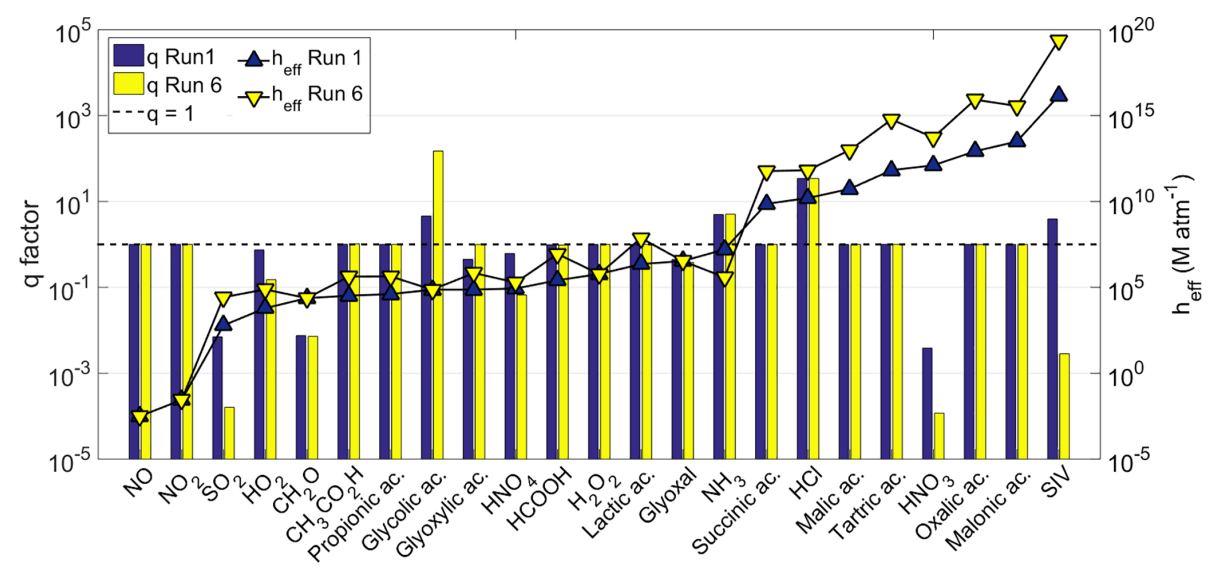

Figure 7. Effective Henry's law constant $\left(H_{\text {eff }}\right)$ and partitioning coefficient $q$ calculated for a selection of compounds during Runs 1 (reference) and $6(\mathrm{pH}=6)$. Data for effective Henry's law constants are artificially linked for more clarity.

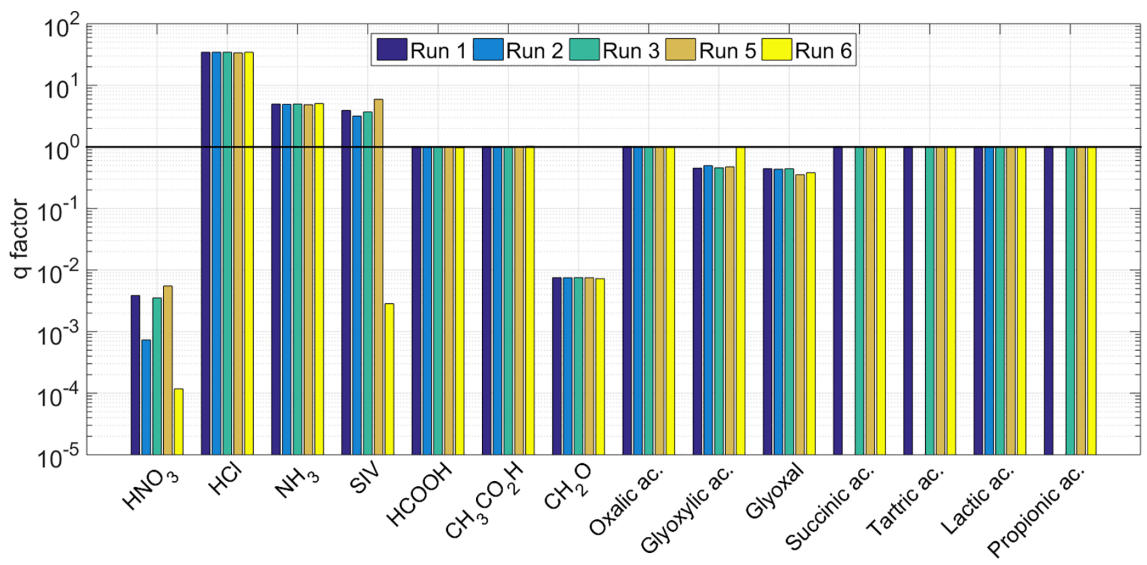

Figure 8. Partitioning coefficients $q$ (log scale) calculated for a selection of compounds during Run 1 (reference), Run 2 (no particle scavenging), Run 3 (increased quantities of organics in the particle phase), Run 5 (decreased cloud liquid water content and droplet radius) and Run $6(\mathrm{pH}=6)$.

To complete the discussion, the $q$ factors calculated during the different runs are shown in Fig. 8. Strong acids such as nitric acid or sulfuric acid are sensitive to the cloud LWC and droplet radius, as observed when comparing Run 1 and Run 5, and they are produced less efficiently under higher $\mathrm{pH}$ (Run 6). Particle nucleation scavenging is an important source of nitric acid in the cloud, and neglecting it (Run 2) leads to a strong undersaturation of nitric acid in the cloud water compared to in Run 1. In contrast, there is no difference observed between the various runs for the carboxylic acids, which essentially originate from particle scavenging.

\subsubsection{Sources}

The contributions of the gaseous, particulate and aqueous concentrations to the total atmospheric concentration of a given species can be evaluated from measurements within the experimental uncertainties. It is, however, difficult to evaluate with an experimental procedure how particle scavenging and mass transfer from the gas-phase and aqueous-phase reactions influence the aqueous concentrations. The model is a complementary tool that can provide such information. Figure 9 shows the origin of species in cloud water for Run 3. For a given compound, the contribution of each source (particulate scavenging, mass transfer from the gas-phase and aqueous-phase reactivity) was calculated as the ratio of its corresponding production rate (averaged over cloud lifetime) over the total production rate.

The ammonia and formic acid molecules that are found in the aqueous phase mainly come from the gas phase, while sulfuric and acetic acids are formed through reactivity in the aqueous phase. Malonic acid exclusively originates from particle scavenging; the same applies for oxalic acid when ironoxalate chemistry is activated. In contrast, aqueous reactivity is the major source of oxalic acid when iron complexation by oxalate is not considered. As expected, $\mathrm{C}_{3}-\mathrm{C}_{4}$ carboxylic acids come mainly from particle scavenging, as shown in Fig. 9 for malonic acid. For acetic acid, the contributions of 


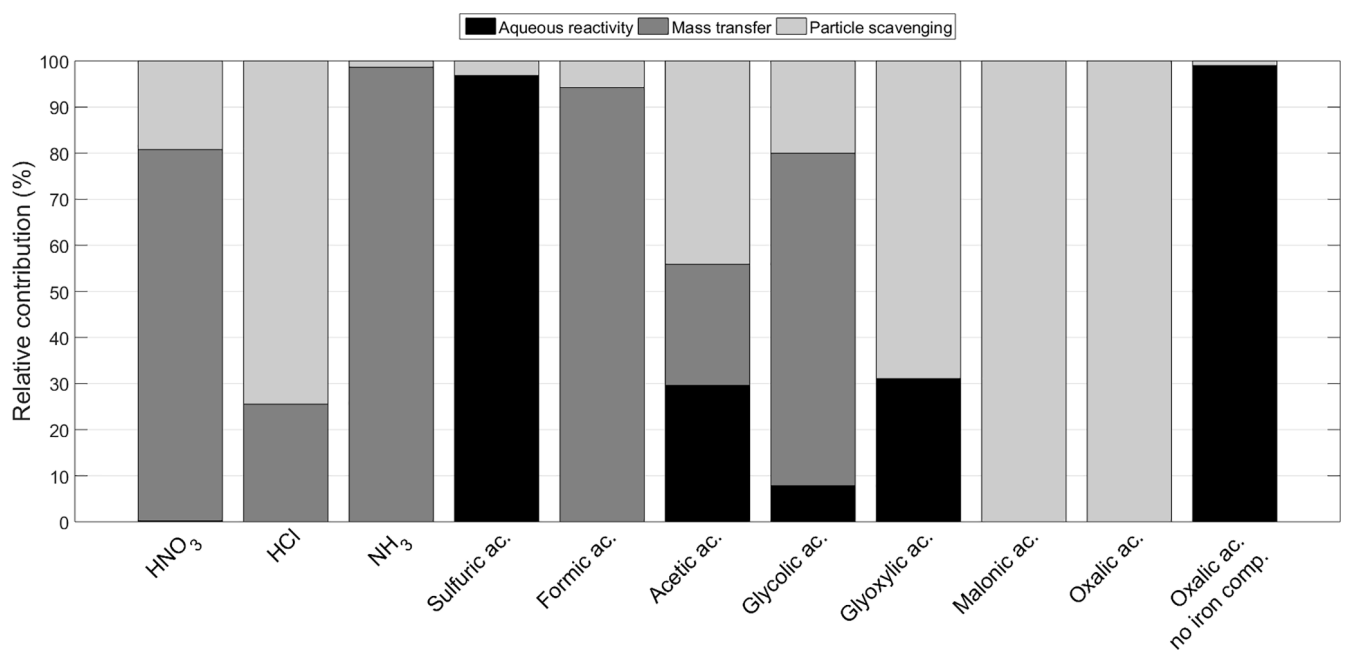

Figure 9. Relative contributions of particle scavenging, mass transfer and aqueous reactivity to the production of selected compounds during Run 3 (increased quantities of organics in the particle phase).

the three sources are more equally distributed. Their relative efficiency, however, varies as a function of the $\mathrm{pH}$ since the production of acetic acid by aqueous-phase reactivity in the cloud water is $\mathrm{pH}$-dependent. The relative contributions of the three sources to the concentration of acetic acid in cloud water are $42.3,43$ and $14.7 \%$ in Run 1 (pH approximately 4.3), while they are $34.6,54.6$ and $10.8 \%$ in $\mathrm{Run} 6(\mathrm{pH}=6)$, for aqueous-phase reactivity, mass transfer and particle scavenging, respectively.

\section{Conclusion}

To describe the cloud multiphase system, the chemical model CLEPS 1.0 (Mouchel-Vallon et al., 2017), which describes the oxidation of isoprene into water-soluble organic species, has been coupled with the warm microphysical scheme module previously presented by Leriche et al. (2007). In the present study, the activation of aerosol particles into cloud droplets has been updated to account for the influence of organic surfactants (Abdul-Razzak and Ghan, 2004). Among organics, dicarboxylic acids were previously found to enhance the particles' $\mathrm{CCN}$ efficiency; thus, their contribution to the particle composition was explicitly accounted for. CLEPS 1.0 has been extended (CLEPS 1.1) to include the aqueous chemistry of these dicarboxylic acids originating from the particulate phase (succinic, malic, tartric and fumaric-maleic acids) following the protocol described by Mouchel-Vallon et al. (2017). The new coupled model then has the ability to calculate the aqueous-phase concentrations of compounds originating from particle scavenging, mass transfer from the gas phase and the in-cloud chemical reactivity. It can also predict the partitioning of any chemical species between the gas and aqueous phases, which is not well documented by measurements, as shown in the recent review by Ervens (2015).

The present study aimed at assessing the effect of particle scavenging on the cloud water chemical content. We thus simulated the formation of a non-precipitating orographic cloud representative of those observed at Puy de Dôme from the activation of an aerosol particle spectrum characteristic of the background conditions at this site (Sellegri et al., 2003). The simulated cloud had a liquid water content of $0.4 \mathrm{~g} \mathrm{~m}^{-3}$ and a cloud droplet radius of $10 \mu \mathrm{m}$, close to the values reported by Deguillaume et al. (2014) for the so-called marine and highly marine cloud events (70 samples from 2011 onwards). To be consistent with the usual conditions encountered at the Puy de Dôme station, the gas-phase concentrations were initialized based on low- $\mathrm{NO}_{x}$ scenario conditions in the chemistry model, as previously presented by MouchelVallon et al. (2017).

The model was shown to reproduce the inorganic levels in the cloud well, with the exception of nitrate, which was underestimated because of the low- $\mathrm{NO}_{x}$ conditions. Some discrepancies were also found for $\mathrm{H}_{2} \mathrm{O}_{2}$, most likely arising from both measurement and modeling issues. The missing description of the activity of microorganisms in the model, previously reported to efficiently degrade both hydrogen peroxide and formate (Vaiitilingom et al., 2013), might also explain the overestimated concentrations of those compounds in the model.

In addition to formic acid, for the reference simulation, the model is also capable of simulating organic acid concentrations in agreement with observations, but they are on average in the lower range of the measured values reported by Deguillaume et al. (2014). Several sensitivity tests were performed to further investigate the observed discrepancies, which could finally, to a large extent, be explained by (1) an 
insufficient organic loading in the particle spectrum used to initialize the model and (2) significantly higher acidity in the model compared to measurements. For all these runs, the partitioning ratio is evaluated to be at Henry's law equilibrium for most of the species, more particularly for carboxylic acids originating from the particulate phase. However, some deviations are observed for inorganic species and this deviation increases with increasing $\mathrm{pH}$ (for $\mathrm{HNO}_{3}$ and SIV). Highly soluble carbonyl compounds (glyoxal, formaldehyde, etc.) are undersaturated with respect to the equilibrium predicted by the Henry's law.

Future investigations will be realized on the basis of this coupled model CLEPS 1.1 to include the effects of rain formation, ice microphysics and microbial activity on the organic chemistry in clouds.

Code availability. The mechanism used in this paper is available in KPP format upon request to 1.deguillaume@opgc.univbpclermont.fr. Any suggestions and corrections to the mechanism (e.g., a new experimental rate constant we may have missed, typos) are also welcomed at the same address. The coupled model that was used for the simulations is also available upon request to 1.deguillaume@opgc.univ-bpclermont.fr

\section{The Supplement related to this article is available online at https://doi.org/10.5194/acp-18-2225-2018-supplement.}

Competing interests. The authors declare that they have no conflict of interest.

Acknowledgements. The authors acknowledge Karine Sellegri for data availability on aerosol particles and for helpful discussions. This work was supported by CEA/CNRS through contract CEA 12-27-C-DSPG/CAJ - CNRS 77265. The authors are also very grateful to the Agence Nationale de la Recherche (ANR) for its financial support through the BIOCAP project (ANR-13-BS060004).

Edited by: David Topping

Reviewed by: two anonymous referees

\section{References}

Abbatt, J. P. D., Broekhuizen, K., and Pradeep Kumar, P.: Cloud condensation nucleus activity of internally mixed ammonium sulfate/organic acid aerosol particles, Atmos. Environ., 39, 4767-4778, https://doi.org/10.1016/j.atmosenv.2005.04.029, 2005.

Abdul-Razzak, H. and Ghan, S. J.: A parameterization of aerosol activation: 2. Multiple aerosol types, J. Geophys. Res.-Atmos., 105, 6837-6844, https://doi.org/10.1029/1999JD901161, 2000.
Abdul-Razzak, H. and Ghan, S. J.: Parameterization of the influence of organic surfactants on aerosol activation, J. Geophys. Res.Atmos., 109, D03205, https://doi.org/10.1029/2003JD004043, 2004.

Abdul-Razzak, H., Ghan, S. J., and Rivera-Carpio, C.: A parameterization of aerosol activation: 1. Single aerosol type, J. Geophys. Res.-Atmos., 103, 6123-6131, https://doi.org/10.1029/97JD03735, 1998.

Asmi, E., Freney, E., Hervo, M., Picard, D., Rose, C., Colomb, A., and Sellegri, K.: Aerosol cloud activation in summer and winter at puy-de-Dôme high altitude site in France, Atmos. Chem. Phys., 12, 11589-11607, https://doi.org/10.5194/acp-12-115892012, 2012.

Audiffren, N., Renard, M., Buisson, E., and Chaumerliac, N.: Deviations from the Henry's law equilibrium during cloud events: a numerical approach of the mass transfer between phases and its specific numerical effects, Atmos. Res., 49, 139-161, https://doi.org/10.1016/S0169-8095(98)00072-6, 1998.

Berry, E. X. and Reinhardt, R. L.: An analysis of cloud drop growth by collection. Part I. Double distributions, J. Atmos. Sci., 31, 1814-1824, 1974a.

Berry, E. X. and Reinhardt, R. L.: An analysis of cloud drop growth by collection. Part II. Single initial distributions, J. Atmos. Sci., 31, 1825-1831, 1974b.

Berry, E. X. and Reinhardt, R. L.: An analysis of cloud drop growth by collection. Part III. Accretion and self-collection, J. Atmos. Sci., 31, 2118-2126, 1974c.

Berry, E. X. and Reinhardt, R. L.: An analysis of cloud drop growth by collection. Part IV. A new parameterization, J. Atmos. Sci., 31, 2127-2135, 1974d.

Caro, D., Wobrock, W., Flossmann, A. I. and Chaumerliac, N.: A two-moment parameterization of aerosol nucleation and impaction scavenging for a warm cloud microphysics: description and results from a two-dimensional simulation, Atmos. Res., 70, 171-208, https://doi.org/10.1016/j.atmosres.2004.01.002, 2004.

Chameides, W. L.: The photochemistry of a remote marine stratiform cloud, J. Geophys. Res.-Atmos., 89, 4739-4755, https://doi.org/10.1029/JD089iD03p04739, 1984.

Chaumerliac, N., Richard, E., Pinty, J.-P., and Nickerson, E. C.: Sulfur scavenging in a mesoscale model with quasispectral microphysics: Two-dimensional results for continental and maritime clouds, J. Geophys. Res.-Atmos., 92, 3114-3126, https://doi.org/10.1029/JD092iD03p03114, 1987.

Chebbi, A. and Carlier, P.: Carboxylic acids in the troposphere, occurrence, sources, and sinks: A review, Atmos. Environ., 30, 4233-4249, 1996.

Clegg, S. L., Brimblecombe, P., and Khan, I.: The Henry's law constant of oxalic acid and its partitioning into the atmospheric aerosol, Idojárás, 100, 51-68, 1996.

Corrin, M. L. and Harkins, W. D.: The Effect of Salts on the Critical Concentration for the Formation of Micelles in Colloidal Electrolytes1, J. Am. Chem. Soc., 69, 683-688, 1947.

Dabek-Zlotorzynska, E. and McGrath, M.: Determination of lowmolecular-weight carboxylic acids in the ambient air and vehicle emissions: a review, Fresenius J. Anal. Chem., 367, 507-518, https://doi.org/10.1007/s002160000376, 2000.

Damian, V., Sandu, A., Damian, M., Potra, F., and Carmichael, G. R.: The kinetic preprocessor KPP-a software environment for 
solving chemical kinetics, Comput. Chem. Eng., 26, 1567-1579, https://doi.org/10.1016/S0098-1354(02)00128-X, 2002.

Deguillaume, L., Leriche, M., Monod, A., and Chaumerliac, N.: The role of transition metal ions on $\mathrm{HO}_{x}$ radicals in clouds: a numerical evaluation of its impact on multiphase chemistry, Atmos. Chem. Phys., 4, 95-110, https://doi.org/10.5194/acp-4-95-2004, 2004.

Deguillaume, L., Leriche, M., Desboeufs, K., Mailhot, G., George, C., and Chaumerliac, N.: Transition Metals in Atmospheric Liquid Phases: Sources, Reactivity, and Sensitive Parameters, Chem. Rev., 105, 3388-3431, https://doi.org/10.1021/cr040649c, 2005.

Deguillaume, L., Charbouillot, T., Joly, M., Vaïtilingom, M., Parazols, M., Marinoni, A., Amato, P., Delort, A.-M., Vinatier, V., Flossmann, A., Chaumerliac, N., Pichon, J. M., Houdier, S., Laj, P., Sellegri, K., Colomb, A., Brigante, M., and Mailhot, G.: Classification of clouds sampled at the puy de Dôme (France) based on $10 \mathrm{yr}$ of monitoring of their physicochemical properties, Atmos. Chem. Phys., 14, 1485-1506, https://doi.org/10.5194/acp14-1485-2014, 2014.

Djouad, R., Sportisse, B., and Audiffren, N.: Numerical simulation of aqueous-phase atmospheric models: use of a nonautonomous Rosenbrock method, Atmos. Environ., 36, 873-879, https://doi.org/10.1016/S1352-2310(01)00497-6, 2002.

Djouad, R., Michelangeli, D. V., and Gong, W.: Numerical solution for atmospheric multiphase models: Testing the validity of equilibrium assumptions, J. Geophys. Res.-Atmos., 108, 4602, https://doi.org/10.1029/2002JD002969, 2003.

Doussin, J.-F. and Monod, A.: Structure-activity relationship for the estimation of $\mathrm{OH}$-oxidation rate constants of carbonyl compounds in the aqueous phase, Atmos. Chem. Phys., 13, 1162511641, https://doi.org/10.5194/acp-13-11625-2013, 2013.

Emmerson, K. M. and Evans, M. J.: Comparison of tropospheric gas-phase chemistry schemes for use within global models, Atmos. Chem. Phys., 9, 1831-1845, https://doi.org/10.5194/acp-91831-2009, 2009.

Ervens, B.: Modeling the Processing of Aerosol and Trace Gases in Clouds and Fogs, Chem. Rev., 115, 4157-4198, https://doi.org/10.1021/cr5005887, 2015.

Ervens, B., Turpin, B. J., and Weber, R. J.: Secondary organic aerosol formation in cloud droplets and aqueous particles (aqSOA): a review of laboratory, field and model studies, Atmos. Chem. Phys., 11, 11069-11102, https://doi.org/10.5194/acp-1111069-2011, 2011.

Ervens, B., Renard, P., Tlili, S., Ravier, S., Clément, J.-L., and Monod, A.: Aqueous-phase oligomerization of methyl vinyl ketone through photooxidation - Part 2: Development of the chemical mechanism and atmospheric implications, Atmos. Chem. Phys., 15, 9109-9127, https://doi.org/10.5194/acp-159109-2015, 2015.

Fountoukis, C. and Nenes, A.: Continued development of a cloud droplet formation parameterization for global climate models, J. Geophys. Res.-Atmos., 110, D11212, https://doi.org/10.1029/2004JD005591, 2005.

Freney, E. J., Sellegri, K., Canonaco, F., Boulon, J., Hervo, M., Weigel, R., Pichon, J. M., Colomb, A., Prévôt, A. S. H., and Laj, P.: Seasonal variations in aerosol particle composition at the puy-de-Dôme research station in France, Atmos. Chem. Phys., 11, 13047-13059, https://doi.org/10.5194/acp-11-130472011, 2011.
Gelencsér, A. and Varga, Z.: Evaluation of the atmospheric significance of multiphase reactions in atmospheric secondary organic aerosol formation, Atmos. Chem. Phys., 5, 2823-2831, https://doi.org/10.5194/acp-5-2823-2005, 2005.

Gérard, V., Nozière, B., Baduel, C., Fine, L., Frossard, A. A., and Cohen, R. C.: Anionic, Cationic, and Nonionic Surfactants in Atmospheric Aerosols from the Baltic Coast at Askö, Sweden: Implications for Cloud Droplet Activation, Environ. Sci. Technol., 50, 2974-2982, https://doi.org/10.1021/acs.est.5b05809, 2016.

Ghan, S. J., Abdul-Razzak, H., Nenes, A., Ming, Y., Liu, X., Ovchinnikov, M., Shipway, B., Meskhidze, N., Xu, J., and Shi, X.: Droplet nucleation: Physically-based parameterizations and comparative evaluation, J. Adv. Model. Earth Sy., 3, M10001, https://doi.org/10.1029/2011MS000074, 2011.

Ginnebaugh, D. L. and Jacobson, M. Z.: Coupling of highly explicit gas and aqueous chemistry mechanisms for use in 3-D, Atmos. Environ., 62, 408-415, https://doi.org/10.1016/j.atmosenv.2012.08.057, 2012.

Hegg, D. A.: The impact of clouds on aerosol populations, IGAC Activ. Newsl., 23, 3-6, 2001.

Hegg, D. A., Rutledge, S. A. and Hobbs, P. V.: A numerical model for sulfur chemistry in warm-frontal rainbands, J. Geophys. Res.-Atmos., 89, 7133-7147, https://doi.org/10.1029/JD089iD05p07133, 1984.

Herrmann, H., Schaefer, T., Tilgner, A., Styler, S. A., Weller, C., Teich, M., and Otto, T.: Tropospheric Aqueous-Phase Chemistry: Kinetics, Mechanisms, and Its Coupling to a Changing Gas Phase, Chem. Rev., 115, 4259-4334, https://doi.org/10.1021/cr500447k, 2015.

Ip, H. S. S., Huang, X. H. H., and Yu, J. Z.: Effective Henry's law constants of glyoxal, glyoxylic acid, and glycolic acid, Geophys. Res. Lett., 36, L01802, https://doi.org/10.1029/2008GL036212, 2009.

Jenkin, M. E., Young, J. C., and Rickard, A. R.: The MCM v3.3.1 degradation scheme for isoprene, Atmos. Chem. Phys., 15, 11433-11459, https://doi.org/10.5194/acp-15-11433-2015, 2015.

Kanakidou, M., Seinfeld, J. H., Pandis, S. N., Barnes, I., Dentener, F. J., Facchini, M. C., Van Dingenen, R., Ervens, B., Nenes, A., Nielsen, C. J., Swietlicki, E., Putaud, J. P., Balkanski, Y., Fuzzi, S., Horth, J., Moortgat, G. K., Winterhalter, R., Myhre, C. E. L., Tsigaridis, K., Vignati, E., Stephanou, E. G., and Wilson, J.: Organic aerosol and global climate modelling: a review, Atmos. Chem. Phys., 5, 1053-1123, https://doi.org/10.5194/acp-5-10532005, 2005.

Kawamura, K. and Kaplan, I. R.: Motor exhaust emissions as a primary source for dicarboxylic acids in Los Angeles ambient air, Environ. Sci. Technol., 21, 105-110, https://doi.org/10.1021/es00155a014, 1987.

Kawamura, K. and Sakaguchi, F.: Molecular distributions of water soluble dicarboxylic acids in marine aerosols over the Pacific Ocean including tropics, J. Geophys. Res.-Atmos., 104, 35013509, 1999.

Kawamura, K. and Yasui, O.: Diurnal changes in the distribution of dicarboxylic acids, ketocarboxylic acids and dicarbonyls in the urban Tokyo atmosphere, Atmos. Environ., 39, 1945-1960, https://doi.org/10.1016/j.atmosenv.2004.12.014, 2005.

Kawamura, K., Ono, K., Tachibana, E., Charriére, B., and Sempéré, R.: Distributions of low molecular weight dicarboxylic acids, ke- 
toacids and $\alpha$-dicarbonyls in the marine aerosols collected over the Arctic Ocean during late summer, Biogeosciences, 9, 47254737, https://doi.org/10.5194/bg-9-4725-2012, 2012.

Kawamura, K., Tachibana, E., Okuzawa, K., Aggarwal, S. G., Kanaya, Y., and Wang, Z. F.: High abundances of water-soluble dicarboxylic acids, ketocarboxylic acids and $\alpha$-dicarbonyls in the mountaintop aerosols over the North China Plain during wheat burning season, Atmos. Chem. Phys., 13, 8285-8302, https://doi.org/10.5194/acp-13-8285-2013, 2013.

Kerminen, V.-M., Ojanen, C., Pakkanen, T., Hillamo, R., Aurela, M., and Meriläinen, J.: Low-molecular-weight dicarboxylic acids in urban and rural atmosphere, J. Aerosol Sci., 31, 349-362, https://doi.org/10.1016/S0021-8502(99)00063-4, 2000.

Köhler, H.: The nucleus in and the growth of hygroscopic droplets, T. Faraday Soc., 32, 1152-1161, 1936.

Legrand, M., Preunkert, S., Oliveira, T., Pio, C. A., Hammer, S., Gelencsér, A., Kasper-Giebl, A., and Laj, P.: Origin of $\mathrm{C}_{2}-\mathrm{C}_{5}$ dicarboxylic acids in the European atmosphere inferred from year-round aerosol study conducted at a west-east transect, J. Geophys. Res.-Atmos., 112, D23S07, https://doi.org/10.1029/2006JD008019, 2007.

Lelieveld, J. and Crutzen, P. J.: The role of clouds in tropospheric photochemistry, J. Atmos. Chem., 12, 229-267, https://doi.org/10.1007/BF00048075, 1991.

Leriche, M., Chaumerliac, N., and Monod, A.: Coupling quasispectral microphysics with multiphase chemistry: a case study of a polluted air mass at the top of the Puy de Dôme mountain (France), Atmos. Environ., 35, 5411-5423, https://doi.org/10.1016/S1352-2310(01)00300-4, 2001.

Leriche, M., Curier, R. L., Deguillaume, L., Caro, D., Sellegri, K., and Chaumerliac, N.: Numerical quantification of sources and phase partitioning of chemical species in cloud: application to wintertime anthropogenic air masses at the Puy de Dôme station, J. Atmos. Chem., 57, 281-297, https://doi.org/10.1007/s10874007-9073-y, 2007.

Li, Z., Williams, A. L., and Rood, M. J.: Influence of Soluble Surfactant Properties on the Activation of Aerosol Particles Containing Inorganic Solute, J. Atmos. Sci., 55, 1859-1866, https://doi.org/10.1175/15200469(1998)055<1859:IOSSPO>2.0.CO;2, 1998.

Lim, Y. B., Tan, Y., Perri, M. J., Seitzinger, S. P., and Turpin, B. J.: Aqueous chemistry and its role in secondary organic aerosol (SOA) formation, Atmos. Chem. Phys., 10, 1052110539, https://doi.org/10.5194/acp-10-10521-2010, 2010.

Limbeck, A. and Puxbaum, H.: Organic acids in continental background aerosols, Atmos. Environ., 33, 1847-1852, https://doi.org/10.1016/S1352-2310(98)00347-1, 1999.

Ludwig, J. and Klemm, O.: Organic acids in different size classes of atmospheric particulate material, Tellus B, 40, 340-347, 1988.

Mader, B. T., Yu, J. Z., Xu, J. H., Li, Q. F., Wu, W. S., Flagan, R. C., and Seinfeld, J. H.: Molecular composition of the water-soluble fraction of atmospheric carbonaceous aerosols collected during ACE-Asia, J. Geophys. Res.-Atmos., 109, D06206, https://doi.org/10.1029/2003JD004105, 2004.

Madronich, S. and Flocke, S.: Theoretical Estimation of Biologically Effective UV Radiation at the Earth's Surface, in Solar U1traviolet Radiation, edited by: Zerefos, C. S. and Bais, A. F., 2348, Springer Berlin Heidelberg, 1997.
Marinoni, A., Parazols, M., Brigante, M., Deguillaume, L., Amato, P., Delort, A.-M., Laj, P., and Mailhot, G.: Hydrogen peroxide in natural cloud water: Sources and photoreactivity, Atmos. Res., 101, 256-263, https://doi.org/10.1016/j.atmosres.2011.02.013, 2011.

McNeill, V. F., Woo, J. L., Kim, D. D., Schwier, A. N., Wannell, N. J., Sumner, A. J., and Barakat, J. M.: Aqueous-Phase Secondary Organic Aerosol and Organosulfate Formation in Atmospheric Aerosols: A Modeling Study, Environ. Sci. Technol., 46, 80758081, https://doi.org/10.1021/es3002986, 2012.

McNeill, V. F., Sareen, N., and Schwier, A. N.: Surface-active organics in atmospheric aerosols, in: Atmospheric and Aerosol Chemistry, 201-259, Springer, available at: http://link.springer. com/chapter/10.1007/128_2012_404 (last access: 3 June 2016), 2013.

Minakata, D., Li, K., Westerhoff, P., and Crittenden, J.: Development of a Group Contribution Method To Predict Aqueous Phase Hydroxyl Radical (HO) Reaction Rate Constants, Environ. Sci. Technol., 43, 6220-6227, https://doi.org/10.1021/es900956c, 2009.

Mochida, M., Kawabata, A., Kawamura, K., Hatsushika, H., and Yamazaki, K.: Seasonal variation and origins of dicarboxylic acids in the marine atmosphere over the western North Pacific, J. Geophys. Res.-Atmos., 108, 4193, https://doi.org/10.1029/2002JD002355, 2003.

Monod, A. and Doussin, J. F.: Structure-activity relationship for the estimation of $\mathrm{OH}$-oxidation rate constants of aliphatic organic compounds in the aqueous phase: alkanes, alcohols, organic acids and bases, Atmos. Environ., 42, 7611-7622, https://doi.org/10.1016/j.atmosenv.2008.06.005, 2008.

Mouchel-Vallon, C., Deguillaume, L., Monod, A., Perroux, H., Rose, C., Ghigo, G., Long, Y., Leriche, M., Aumont, B., Patryl, L., Armand, P., and Chaumerliac, N.: CLEPS 1.0: A new protocol for cloud aqueous phase oxidation of VOC mechanisms, Geosci. Model Dev., 10, 1339-1362, https://doi.org/10.5194/gmd-10-1339-2017, 2017.

Müller, K., van Pinxteren, D., Plewka, A., Svrcina, B., Kramberger, H., Hofmann, D., Bächmann, K., and Herrmann, H.: Aerosol characterisation at the FEBUKO upwind station Goldlauter (II): Detailed organic chemical characterisation, Atmos. Environ., 39, 4219-4231, https://doi.org/10.1016/j.atmosenv.2005.02.008, 2005.

Nenes, A., Ghan, S., Abdul-Razzak, H., Chuang, P. Y., and Seinfeld, J. H.: Kinetic limitations on cloud droplet formation and impact on cloud albedo, Tellus B, 53, 133-149, 2001.

Nozière, B., Baduel, C., and Jaffrezo, J.-L.: The dynamic surface tension of atmospheric aerosol surfactants reveals new aspects of cloud activation, Nat. Commun., 5, 3335, https://doi.org/10.1038/ncomms4335, 2014.

Phinney, L. A., Lohmann, U., and Leaitch, W. R.: Limitations of using an equilibrium approximation in an aerosol activation parameterization, J. Geophys. Res.-Atmos., 108, 4371, https://doi.org/10.1029/2002JD002391, 2003.

Prisle, N. L., Asmi, A., Topping, D., Partanen, A.-I., Romakkaniemi, S., Dal Maso, M., Kulmala, M., Laaksonen, A., Lehtinen, K. E. J., McFiggans, G., and Kokkola, H.: Surfactant effects in global simulations of cloud droplet activation, Geophys. Res. Lett., 39, L05802, https://doi.org/10.1029/2011GL050467, 2012. 
Raventos-Duran, T., Camredon, M., Valorso, R., Mouchel-Vallon, C., and Aumont, B.: Structure-activity relationships to estimate the effective Henry's law constants of organics of atmospheric interest, Atmos. Chem. Phys., 10, 7643-7654, https://doi.org/10.5194/acp-10-7643-2010, 2010.

Renard, P., Siekmann, F., Salque, G., Demelas, C., Coulomb, B., Vassalo, L., Ravier, S., Temime-Roussel, B., Voisin, D., and Monod, A.: Aqueous-phase oligomerization of methyl vinyl ketone through photooxidation - Part 1: Aging processes of oligomers, Atmos. Chem. Phys., 15, 21-35, https://doi.org/10.5194/acp-15-21-2015, 2015.

Rogge, W. F., Hildemann, L. M., Mazurek, M. A., and Cass, G. R.: Sources of Fine Organic Aerosol. 9. Pine, Oak, and Synthetic Log Combustion in Residential Fireplaces, Environ. Sci. Technol., 32, 13-22, https://doi.org/10.1021/es960930b, 1998.

Saunders, S. M., Pascoe, S., Johnson, A. P., Pilling, M. J., and Jenkin, M. E.: Development and preliminary test results of an expert system for the automatic generation of tropospheric VOC degradation mechanisms, Atmos. Environ., 37, 1723-1735, https://doi.org/10.1016/S1352-2310(03)00072-4, 2003.

Saxena, P. and Hildemann, L. M.: Water-soluble organics in atmospheric particles: A critical review of the literature and application of thermodynamics to identify candidate compounds, J. Atmos. Chem., 24, 57-109, https://doi.org/10.1007/BF00053823, 1996.

Schwartz, S. E.: Mass-Transport Considerations Pertinent to Aqueous Phase Reactions of Gases in Liquid-Water Clouds, in: Chemistry of Multiphase Atmospheric Systems, edited by: Jaeschke, D. W., 415-471, Springer, Berlin Heidelberg, 1986.

Sellegri, K., Laj, P., Peron, F., Dupuy, R., Legrand, M., Preunkert, S., Putaud, J.-P., Cachier, H., and Ghermandi, G.: Mass balance of free tropospheric aerosol at the Puy de Dôme (France) in winter, J. Geophys. Res.-Atmos., 108, 4333, https://doi.org/10.1029/2002JD002747, 2003.

Sempére, R. and Kawamura, K.: Comparative distributions of dicarboxylic acids and related polar compounds in snow, rain and aerosols from urban atmosphere, Atmos. Environ., 28, 449-459, 1994.
Shulman, M. L., Jacobson, M. C., Carlson, R. J., Synovec, R. E., and Young, T. E.: Dissolution behavior and surface tension effects of organic compounds in nucleating cloud droplets, Geophys. Res. Lett., 23, 277-280, 1996.

Simpson, E., Connolly, P., and McFiggans, G.: An investigation into the performance of four cloud droplet activation parameterisations, Geosci. Model Dev., 7, 1535-1542, https://doi.org/10.5194/gmd-7-1535-2014, 2014.

Snider, J. R., Montague, D. C., and Vali, G.: Hydrogen peroxide retention in rime ice, J. Geophys. Res., 97, 7569-7578, 1992.

Sullivan, A. P., Hodas, N., Turpin, B. J., Skog, K., Keutsch, F. N., Gilardoni, S., Paglione, M., Rinaldi, M., Decesari, S., Facchini, M. C., Poulain, L., Herrmann, H., Wiedensohler, A., Nemitz, E., Twigg, M. M., and Collett Jr., J. L.: Evidence for ambient dark aqueous SOA formation in the Po Valley, Italy, Atmos. Chem. Phys., 16, 8095-8108, https://doi.org/10.5194/acp16-8095-2016, 2016.

Szyszkowski, B.: Experimentelle Studien über kapillare Eigenschaften der wasserigen Losungen von Fettsauren, Z. Phys. Chem., 64, 385-414, 1908.

Tilgner, A. and Herrmann, H.: Radical-driven carbonyl-to-acid conversion and acid degradation in tropospheric aqueous systems studied by CAPRAM, Atmos. Environ., 44, 5415-5422, https://doi.org/10.1016/j.atmosenv.2010.07.050, 2010.

Vaïtilingom, M., Deguillaume, L., Vinatier, V., Sancelme, M., Amato, P., Chaumerliac, N., and Delort, A.-M.: Potential impact of microbial activity on the oxidant capacity and organic carbon budget in clouds, P. Natl. Acad. Sci. USA, 110, 559-564, https://doi.org/10.1073/pnas.1205743110, 2013.

van Pinxteren, D., Neusüß, C., and Herrmann, H.: On the abundance and source contributions of dicarboxylic acids in size-resolved aerosol particles at continental sites in central Europe, Atmos. Chem. Phys., 14, 3913-3928, https://doi.org/10.5194/acp-143913-2014, 2014.

Yao, X., Fang, M., and Chan, C. K.: Size distributions and formation of dicarboxylic acids in atmospheric particles, Atmos. Environ., 36, 2099-2107, https://doi.org/10.1016/S1352-2310(02)002303,2002 . 